\title{
What do Apollo impact glasses tell us about post- Copernican impact flux?
}

Presenter: Ya-Huei Huang

Date: November 6, 2018 @ GSA, Indianapolis

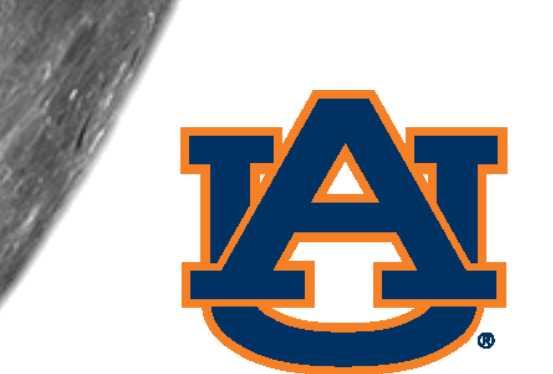

$\frac{\text { AUBURN }}{\text { UNIVERSITY }}$
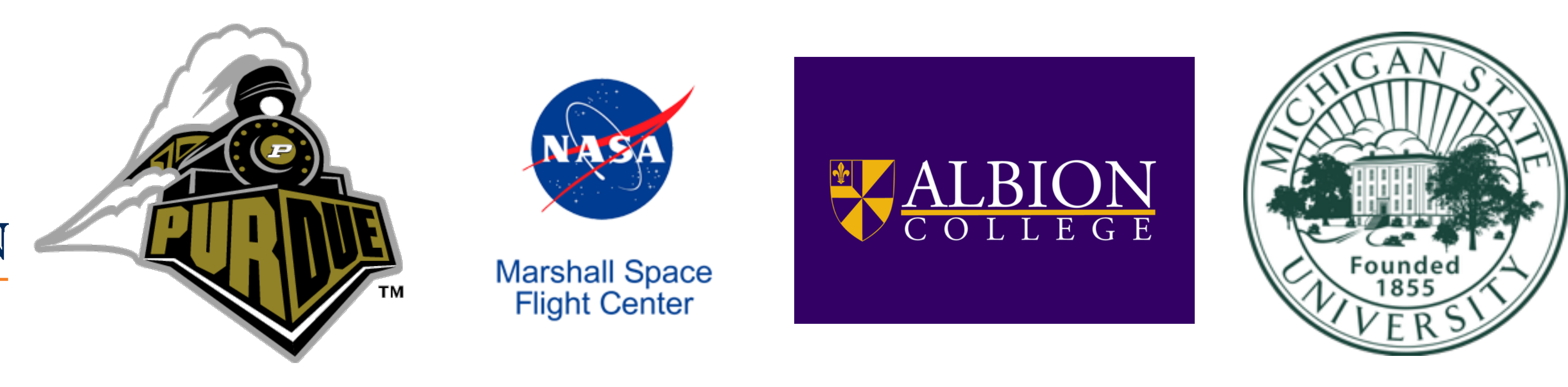

Image credit: NASA/GSFC/Arizona State University

Thanks to my collaborators: David Minton, Nicolle Zellner, Caleb Fassett, Masatoshi Hirabayashi, Jacob Elliott, Pham Qui Nguyen 


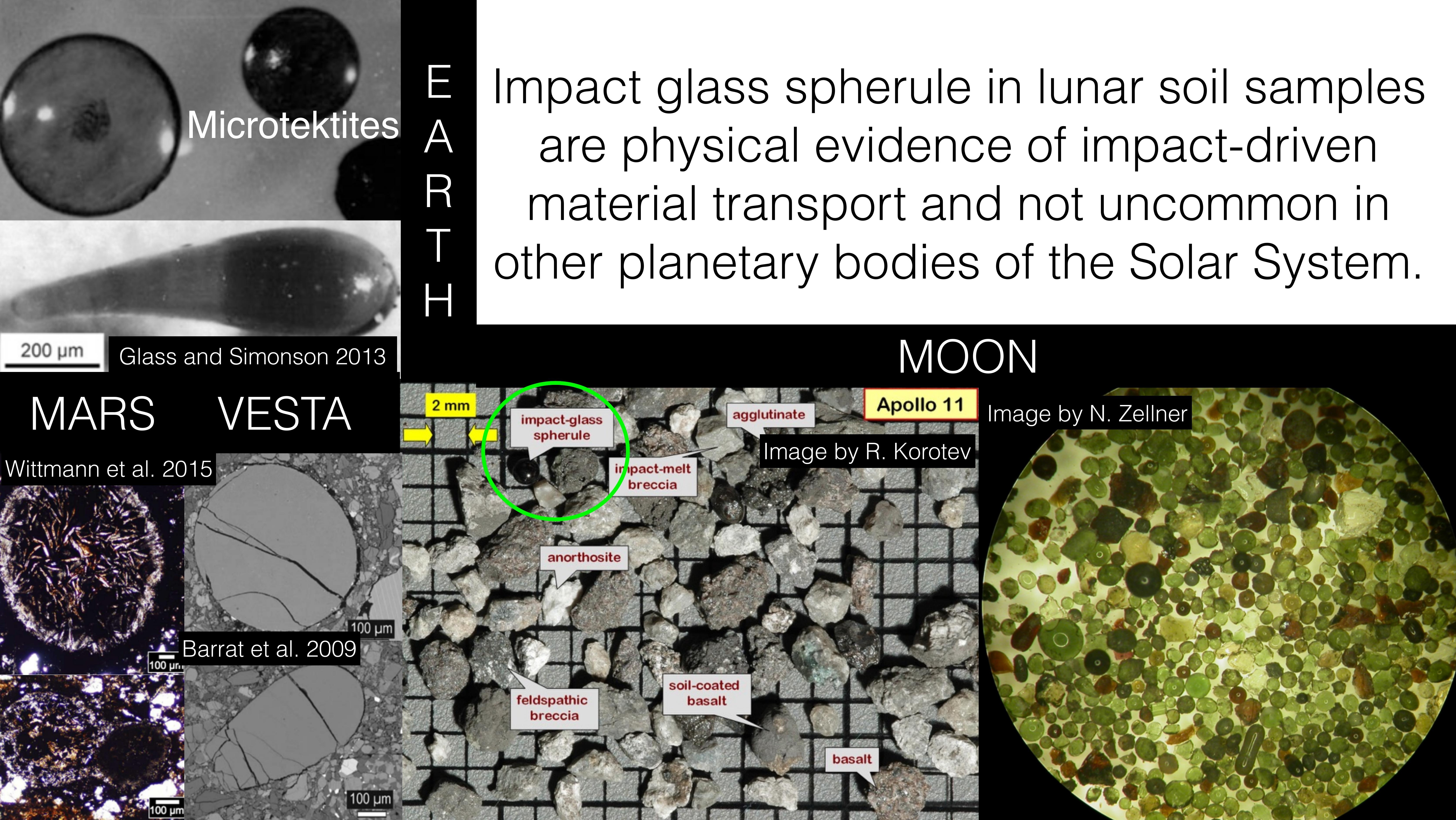






The fact of submillimeter in sizes of impact glass spherules indicates a similar physics process across different planetary bodies that form them. 
The 40Ar-39Ar age distributions of lunar glass spherules in many soil samples show an excess at $<500 \mathrm{Ma}$.

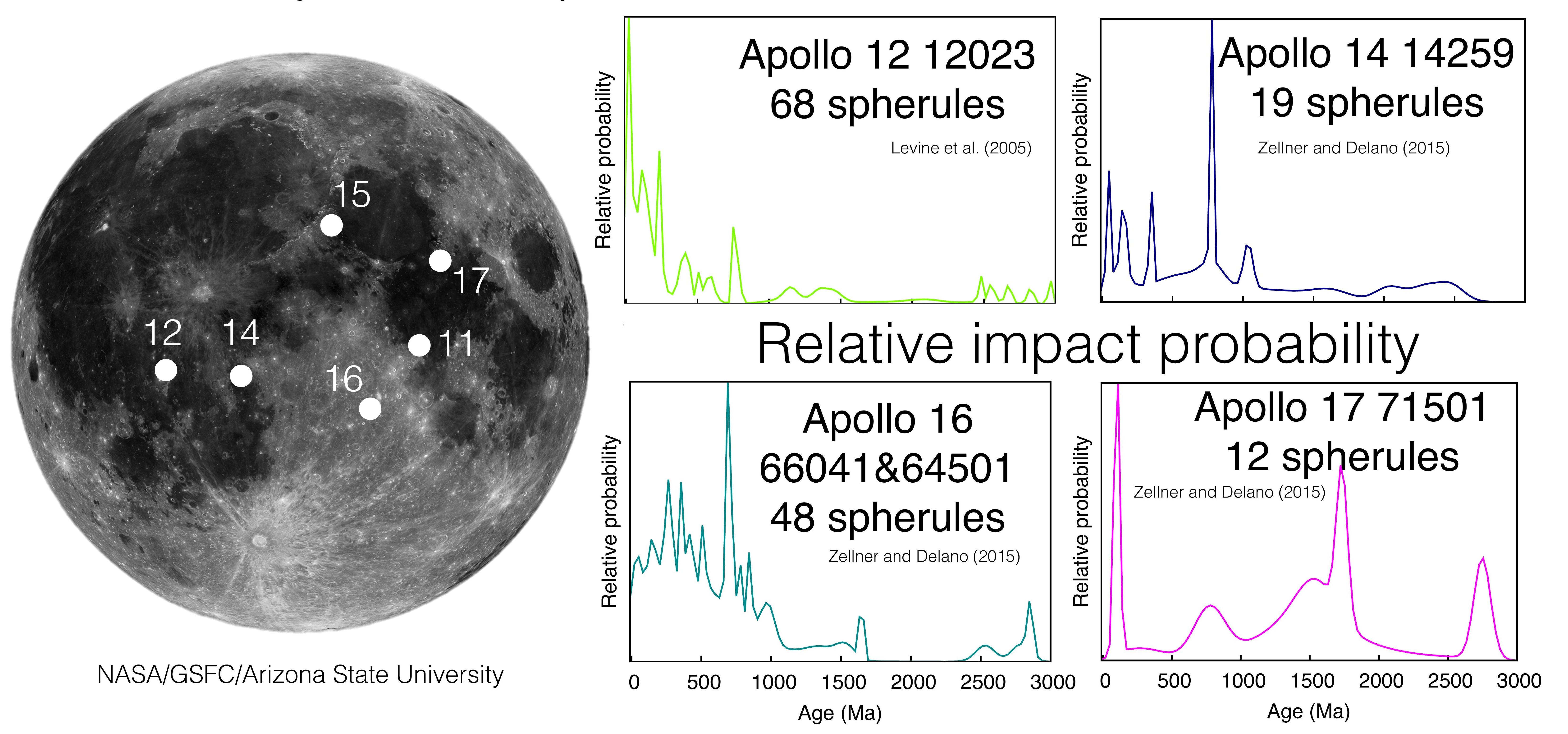


The 40Ar-39Ar age distributions of lunar glass spherules in many soil samples show an excess at $<500 \mathrm{Ma}$.

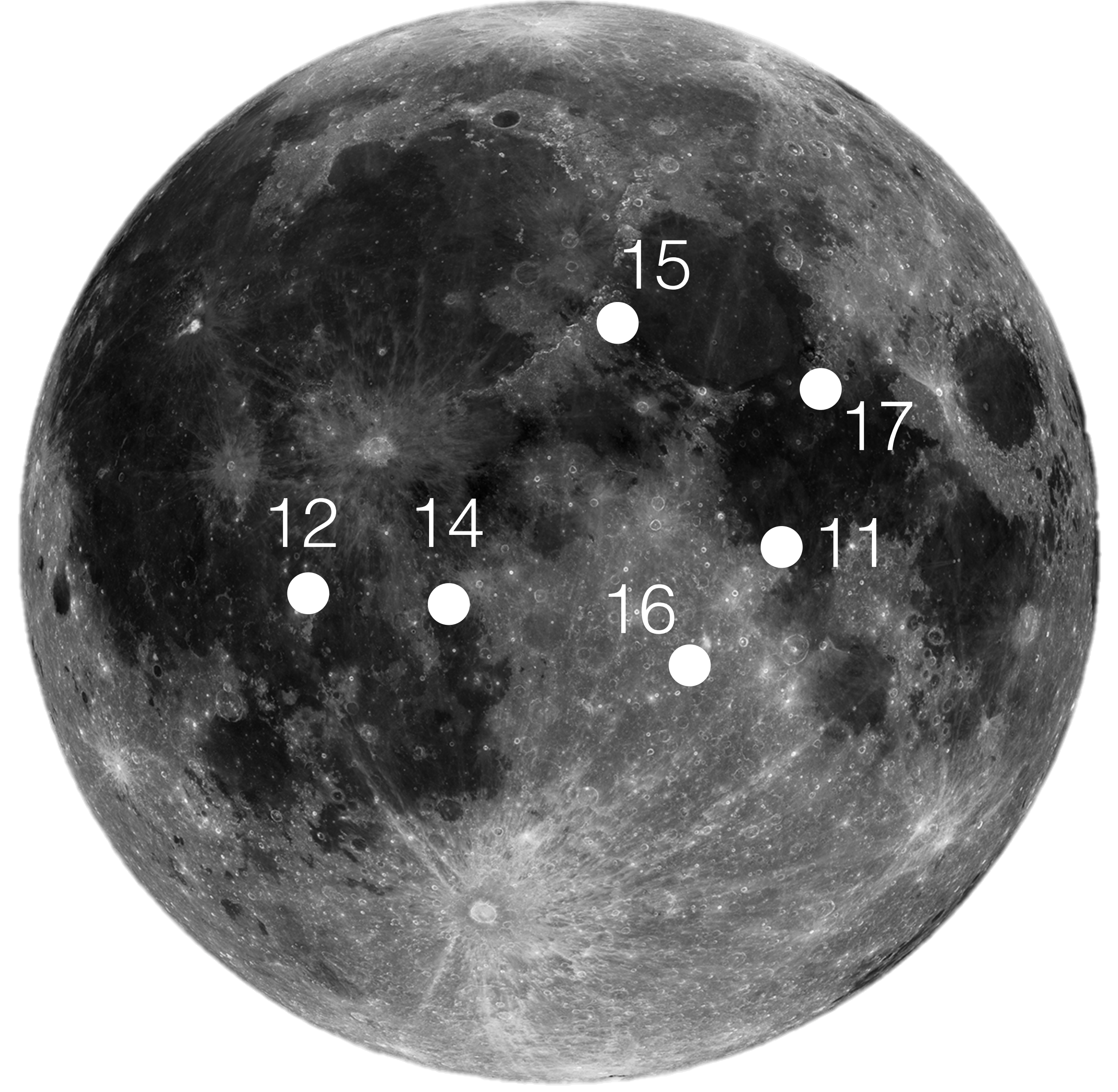

NASA/GSFC/Arizona State University

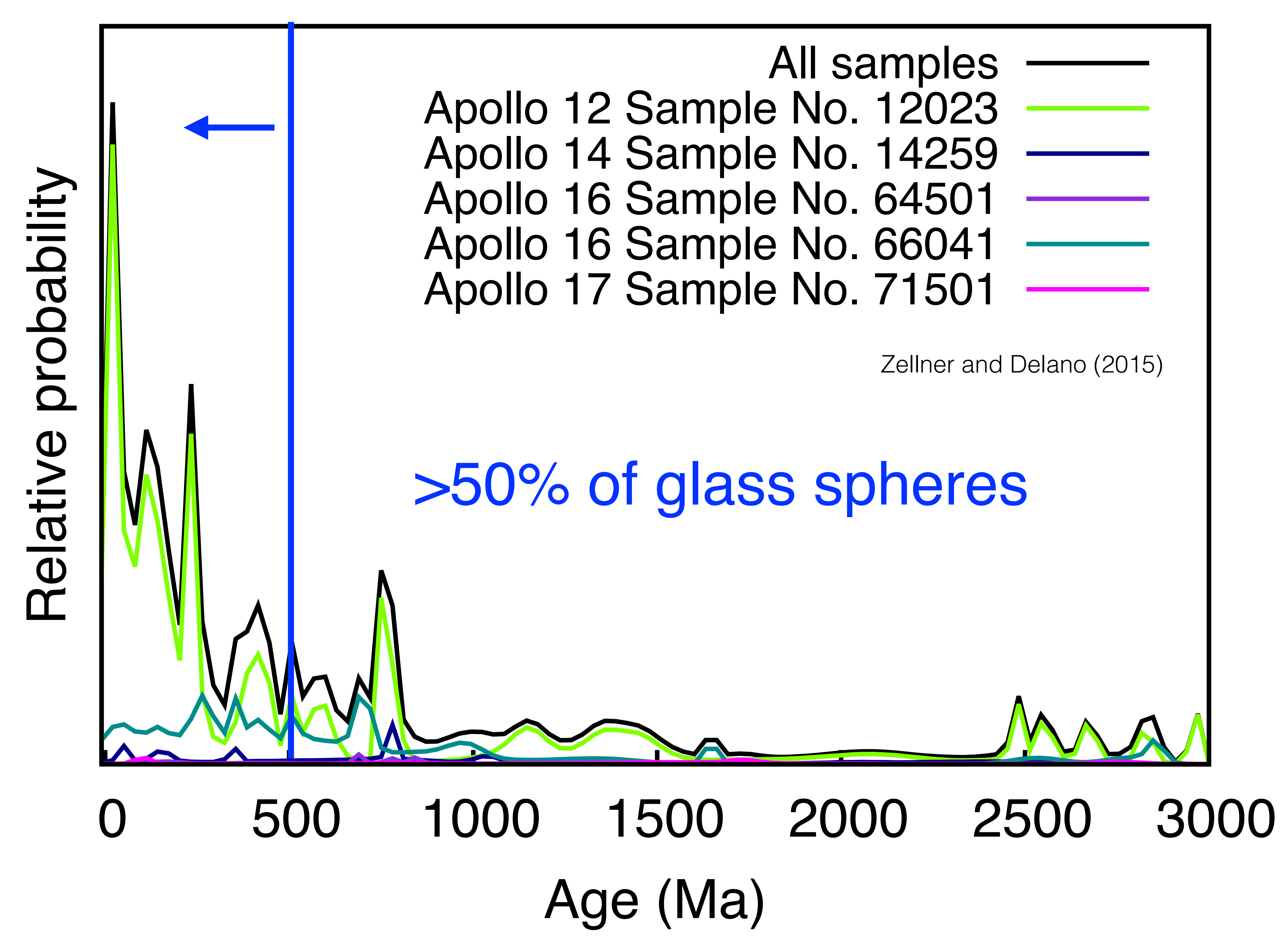


The 40Ar-39Ar age distributions of lunar glass spherules in many soil samples show an excess at $<500 \mathrm{Ma}$.

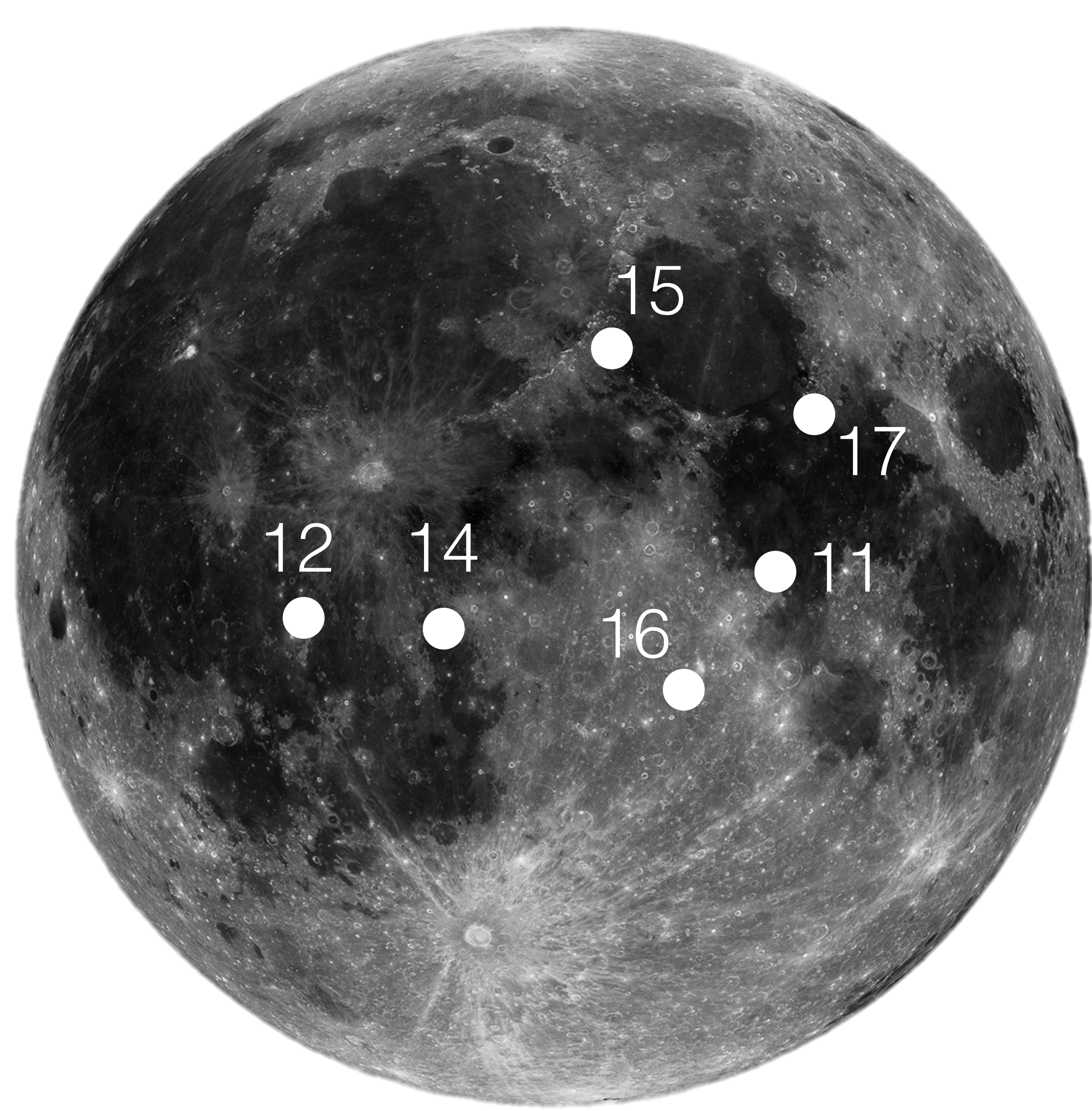

NASA/GSFC/Arizona State University

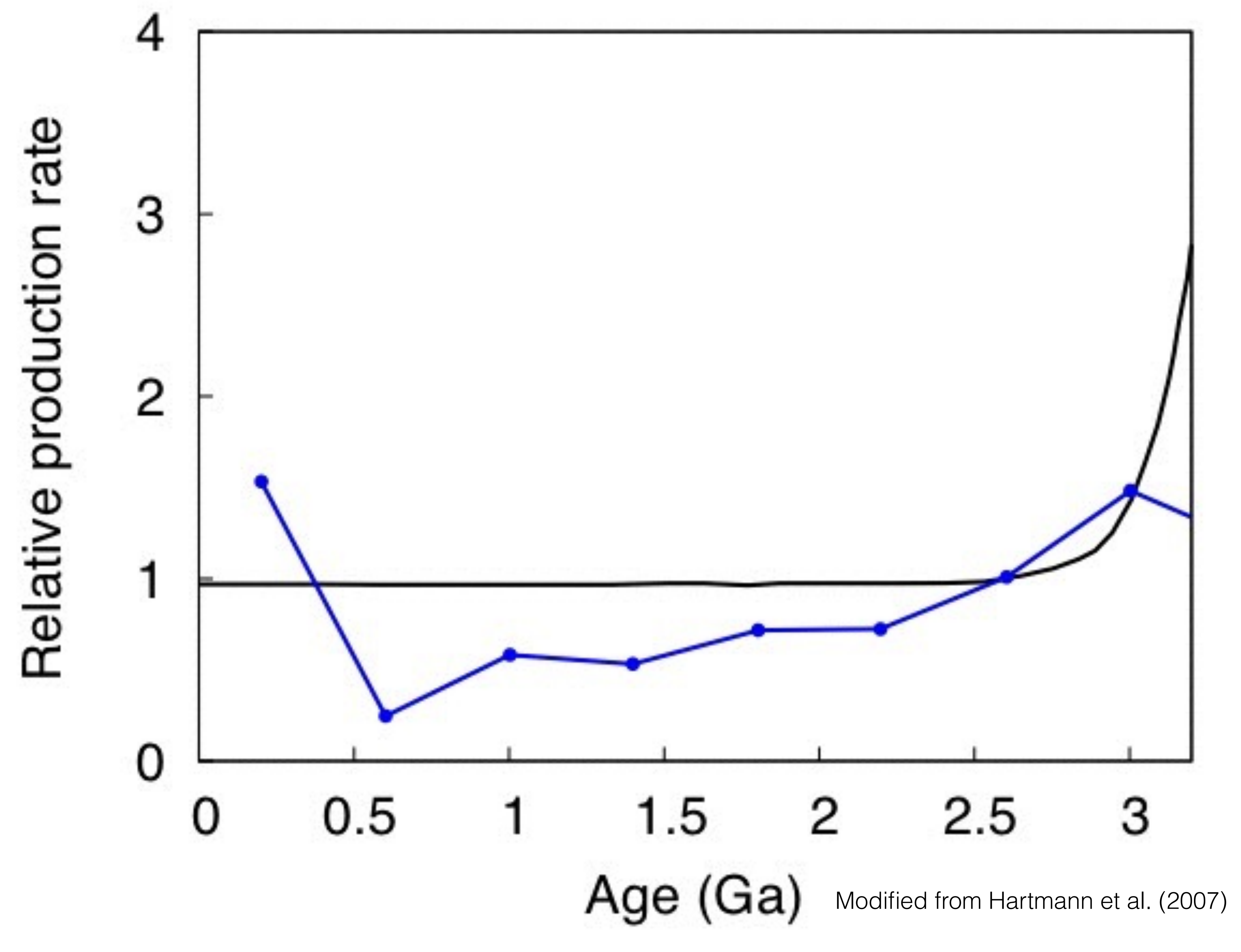


Cratered Terrain Evolution Model (CTEM) is a Monte Carlo code for simulating the heavily-cratered surface and suitable for studying layering dominated environments .

CTEM bombardment simulation

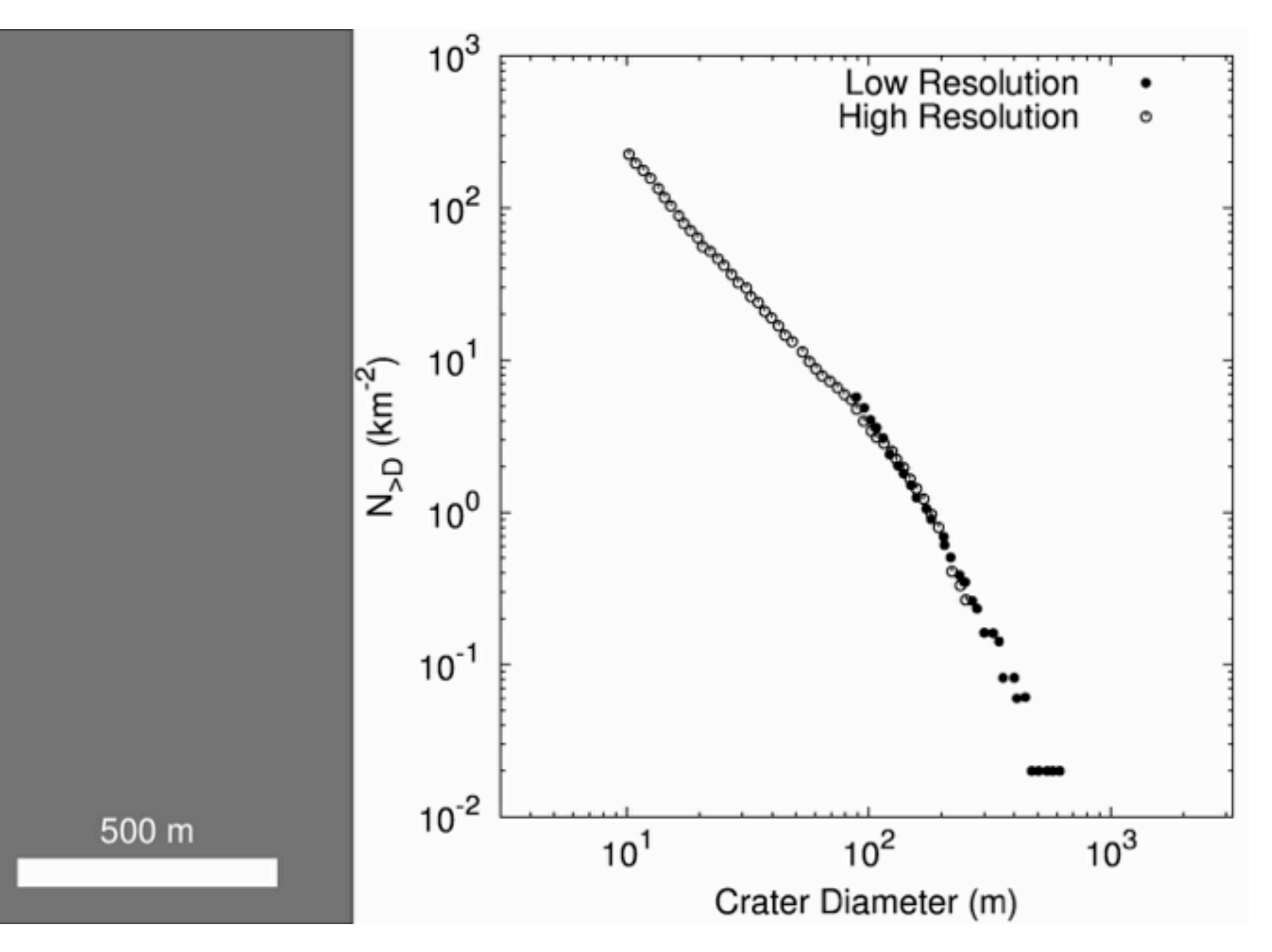

Richardson (2009), Minton et al. (2015), Huang et al. (2017)
CTEM bombardment simulation with a streamline based material tracking system

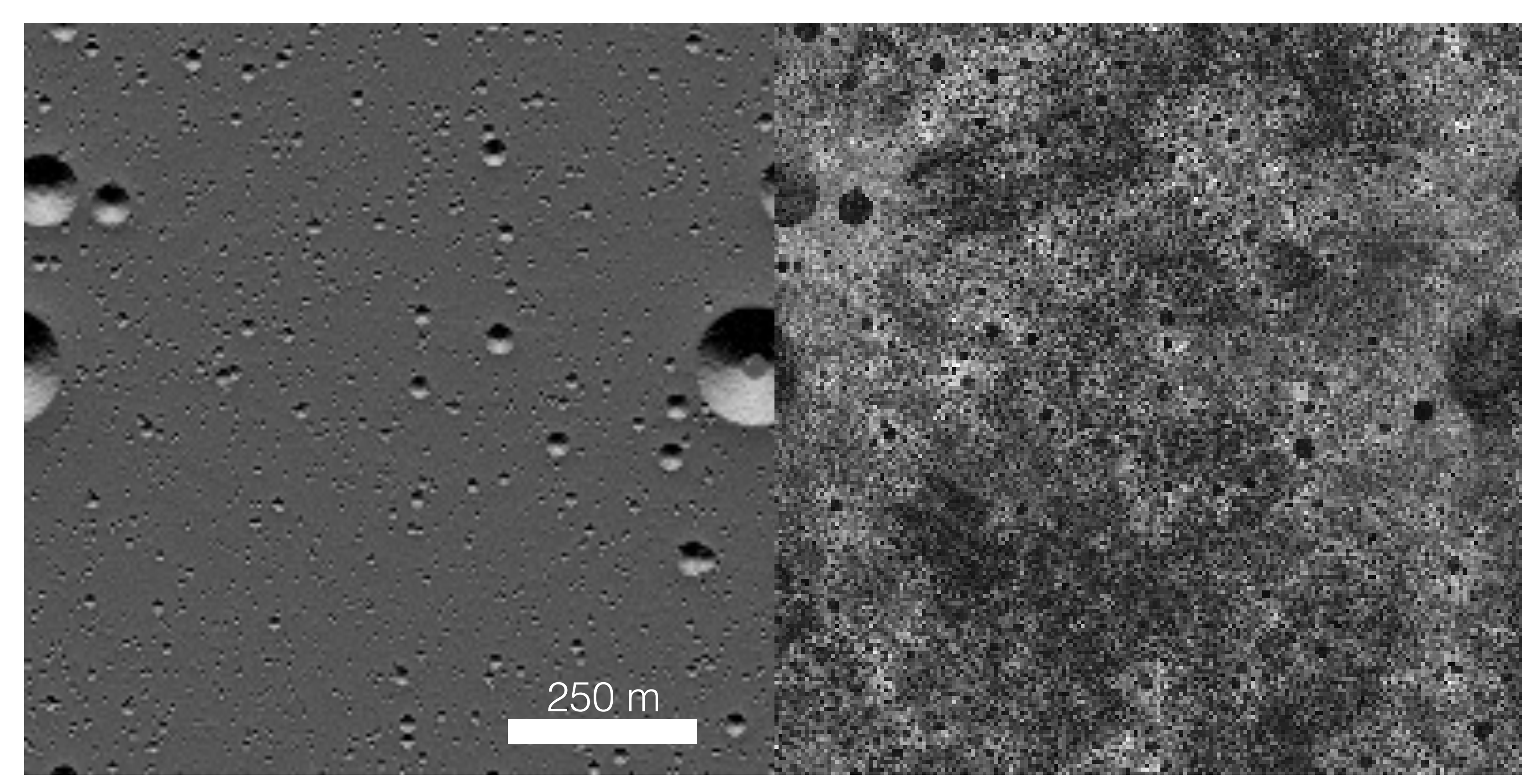

Digital elevation model 
Cratered Terrain Evolution Model (CTEM) is a Monte Carlo code for simulating the heavily-cratered surface and suitable for studying layering dominated environments .

CTEM bombardment simulation

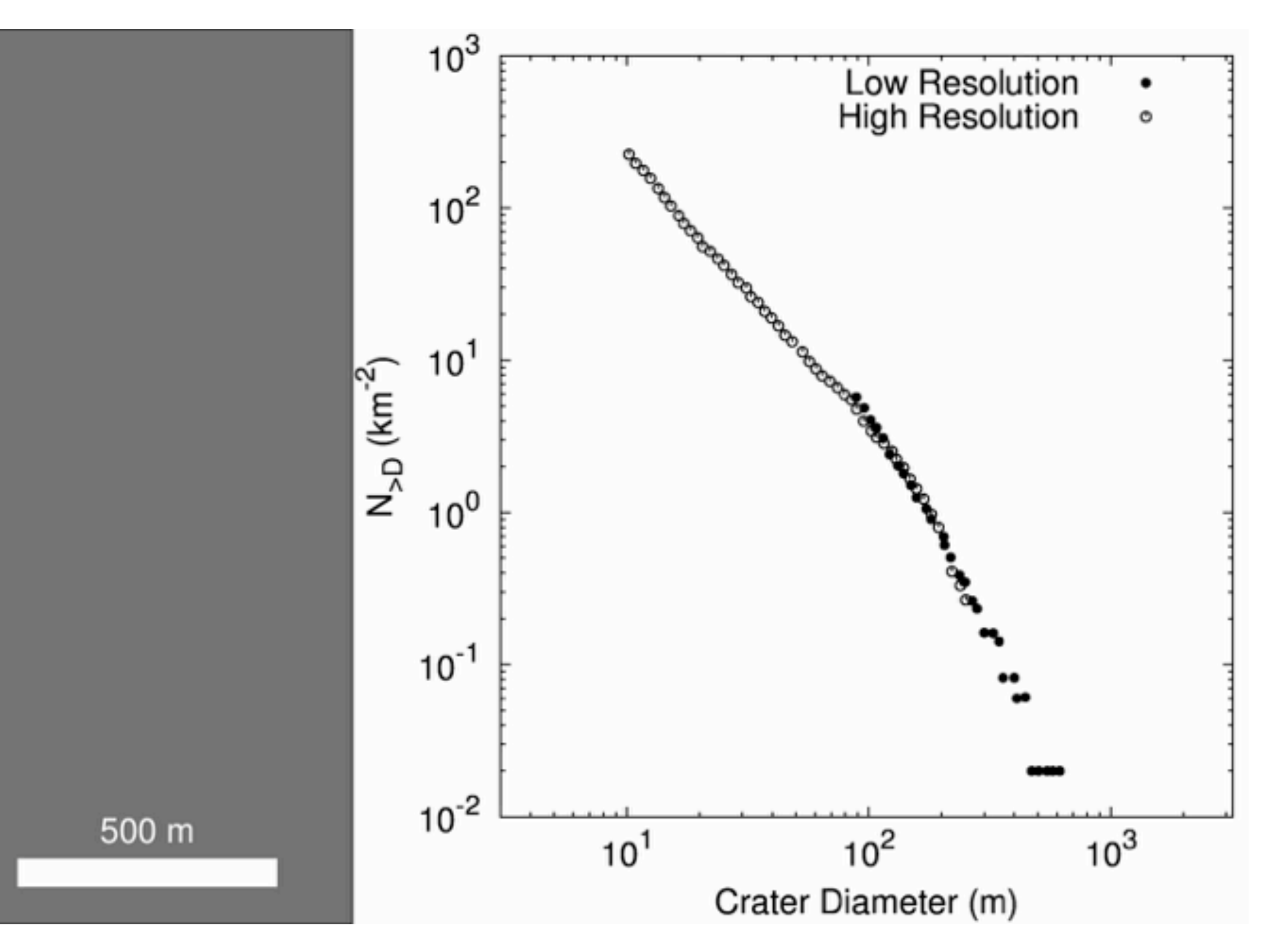

Richardson (2009), Minton et al. (2015), Huang et al. (2017)
CTEM bombardment simulation with a streamline based material tracking system

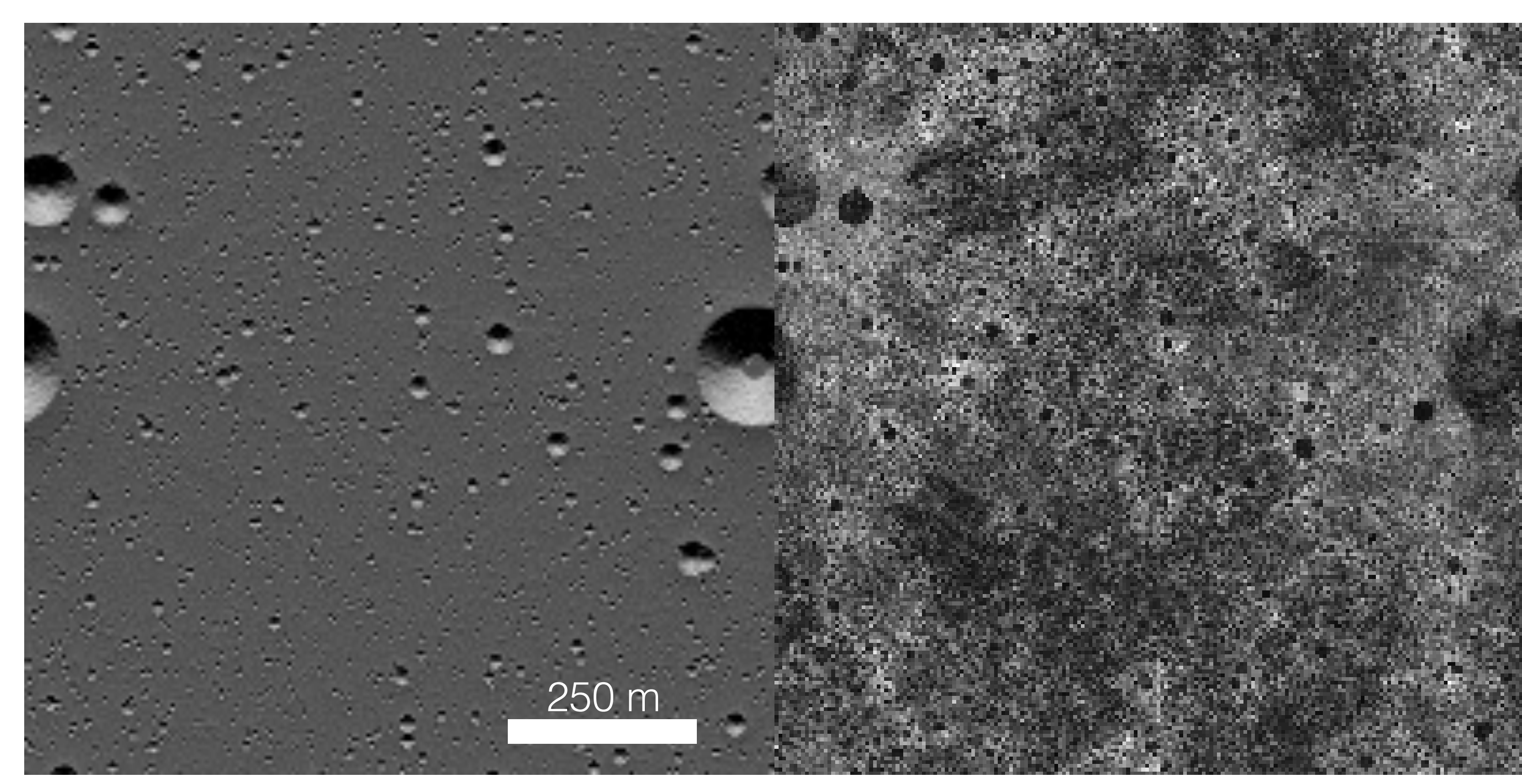

Digital elevation model 
Cratered Terrain Evolution Model (CTEM) is a Monte Carlo code for simulating the heavily-cratered surface and suitable for studying layering dominated environments .

CTEM bombardment simulation

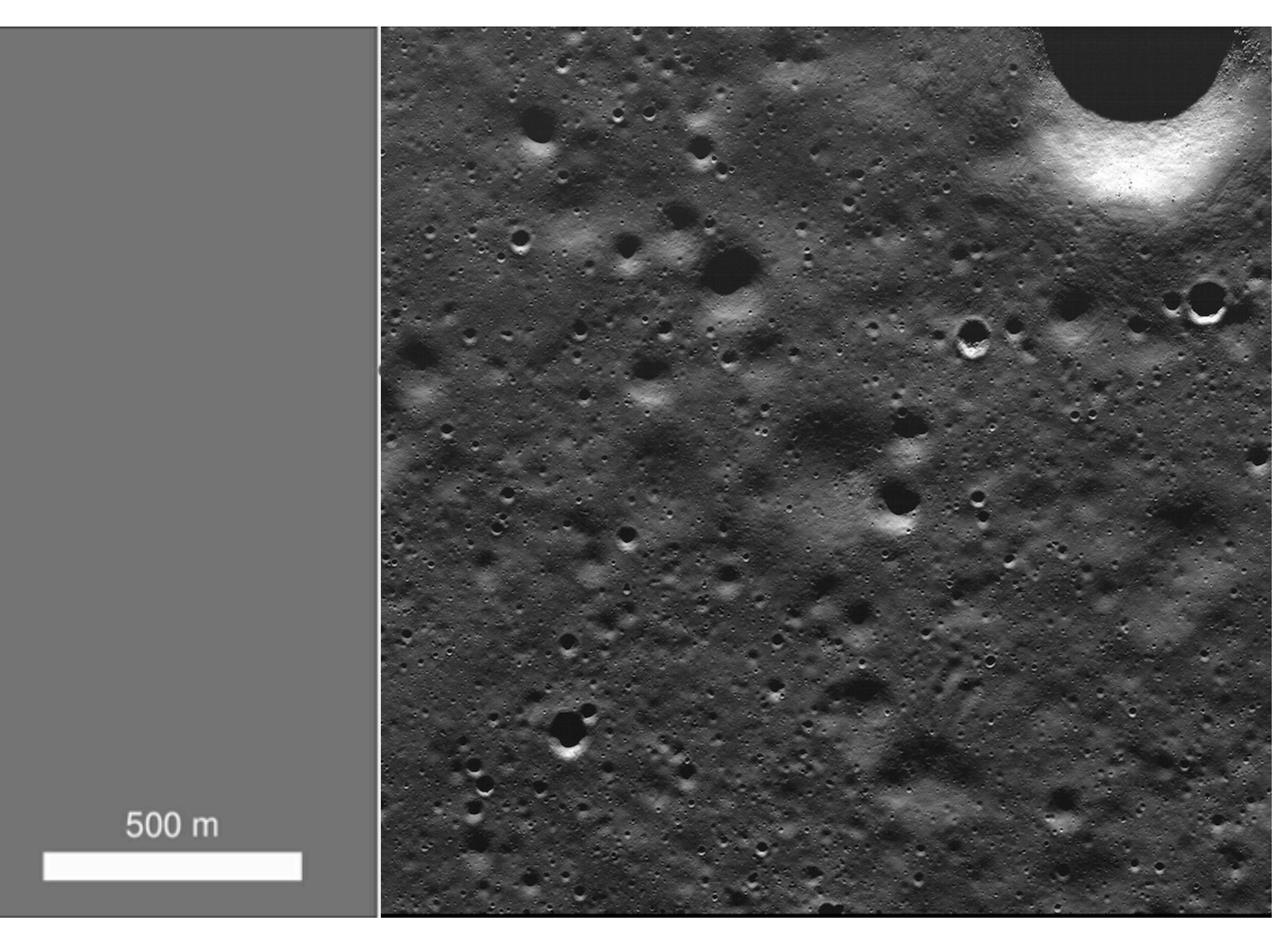

Richardson (2009), Minton et al. (2015), Huang et al. (2017)
CTEM bombardment simulation with a streamline based material tracking system

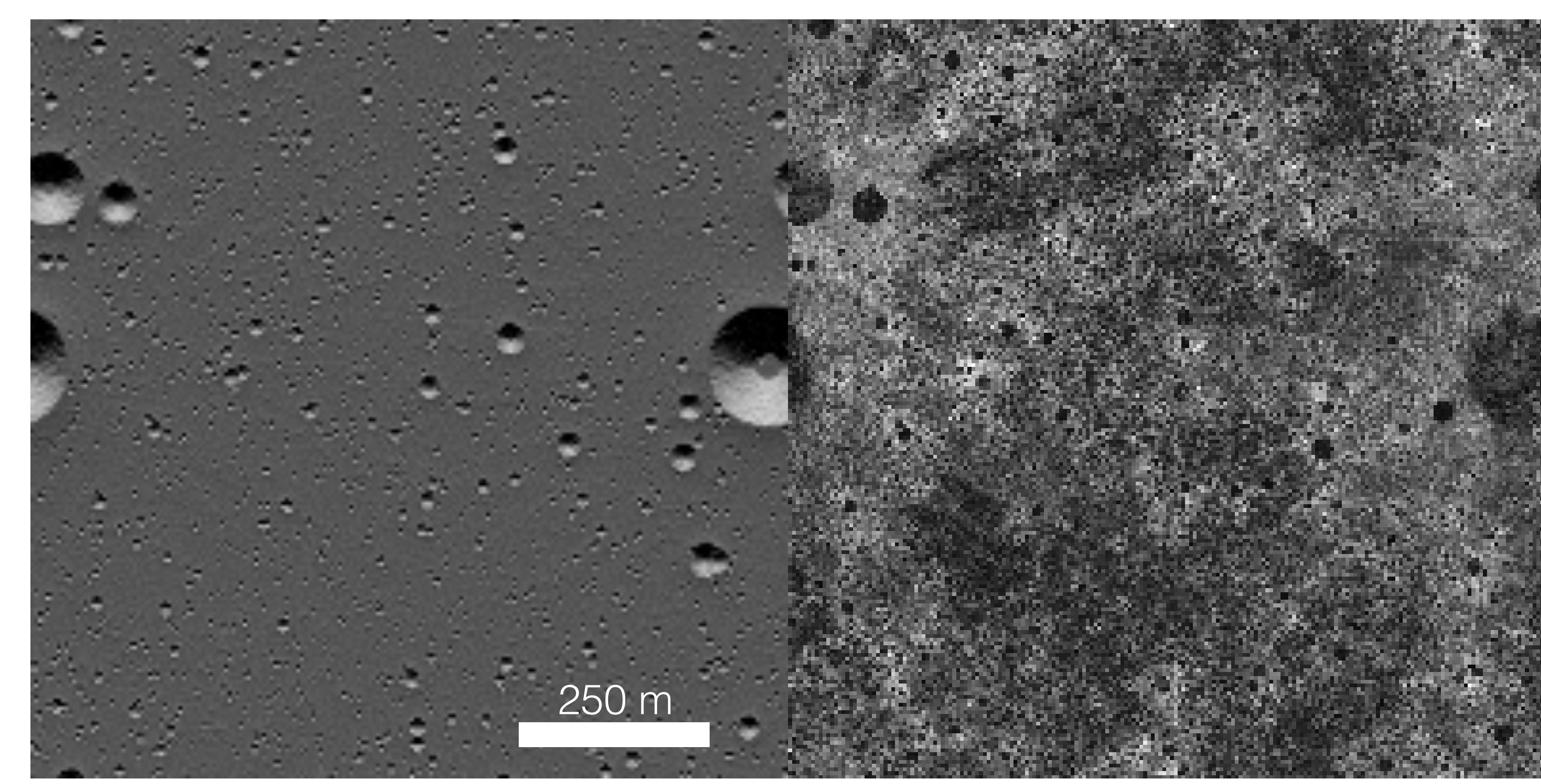

Digital elevation model 


\section{Our model can explain the excess of young spherules in $<500$ Ma without changing the impact flux.}

Observation of five Apollo soil samples
Model result of Model result of numerical samples numerical samples from $10 \mathrm{~cm}$ depths from $1 \mathrm{~m}$ depths
Model result of numerical samples from $3 \mathrm{~m}$ depths

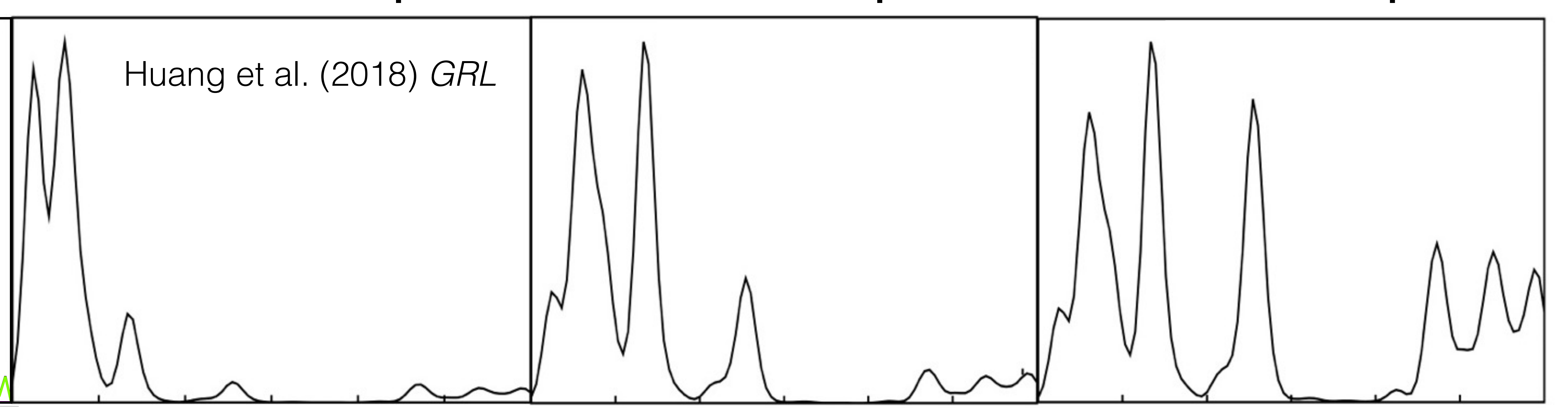

50010001500200025003000 Age (Ma)
50010001500200025003000 Age (Ma)
Age (Ma)

Age (Ma)

This result does not rule out a changing lunar impact, but suggests that this data set is too biased to draw any strong conclusions 


\section{Different spherule populations reveal different age behavior, so we now focus on the "exotic" spherules".}

(1) Sufficient sizes of spherules for argon diffusion loss

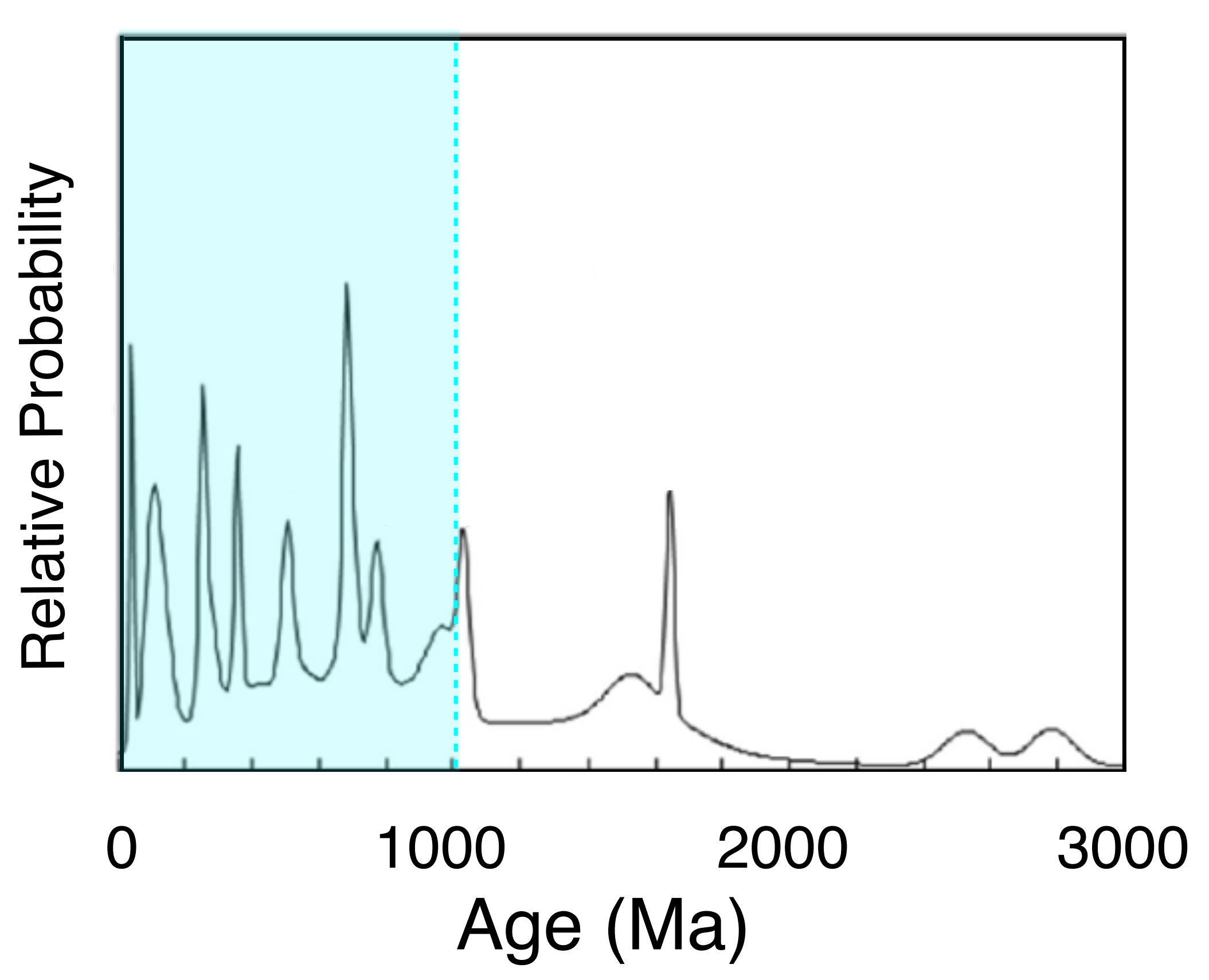

Zellner and Delano (2015) GCA
(2) Spherule age distributions collected from deeper depths

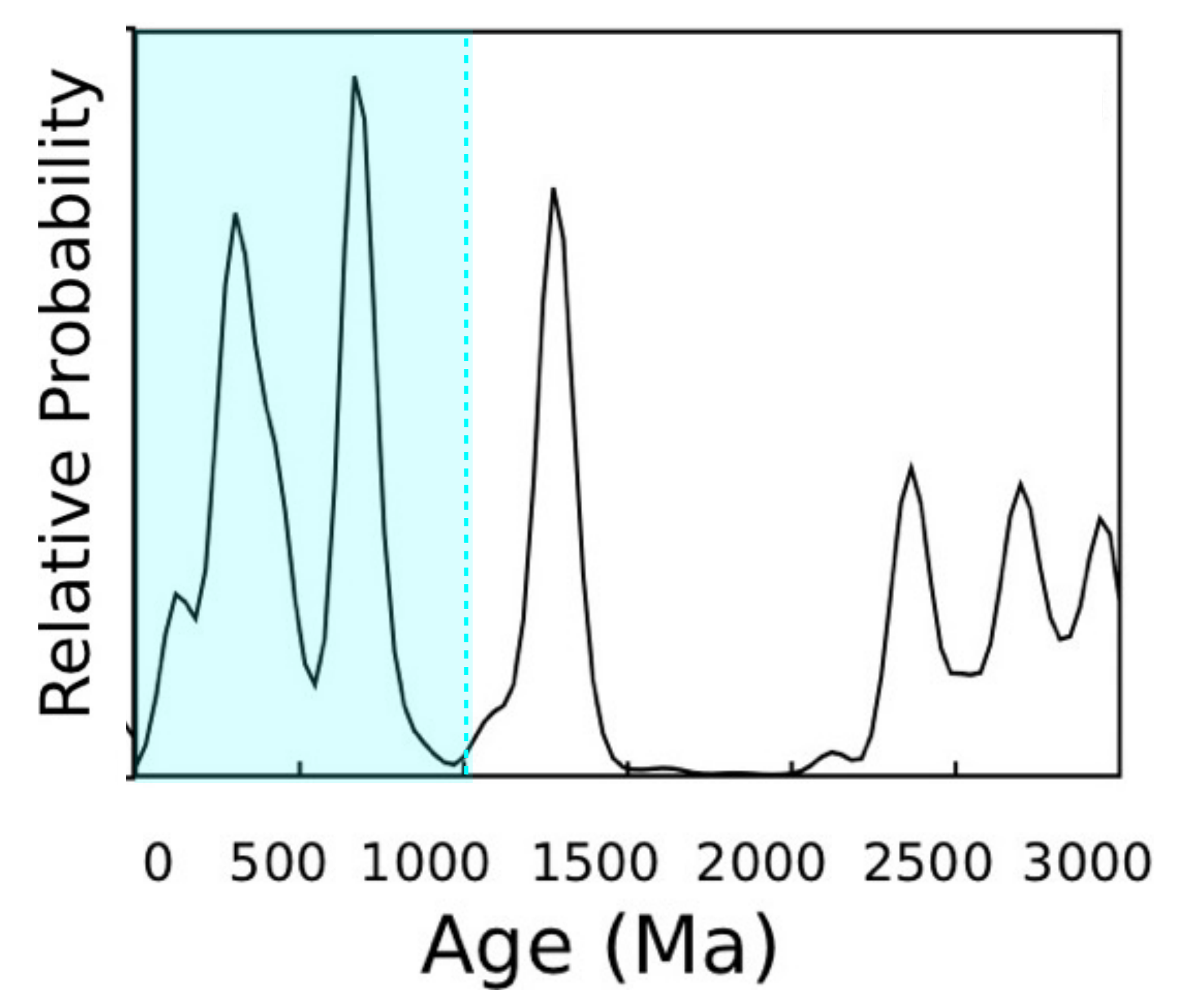

Huang et al. (2018) GRL
(3) Geochemicallydistinct ("exotic") glass spherule age distributions

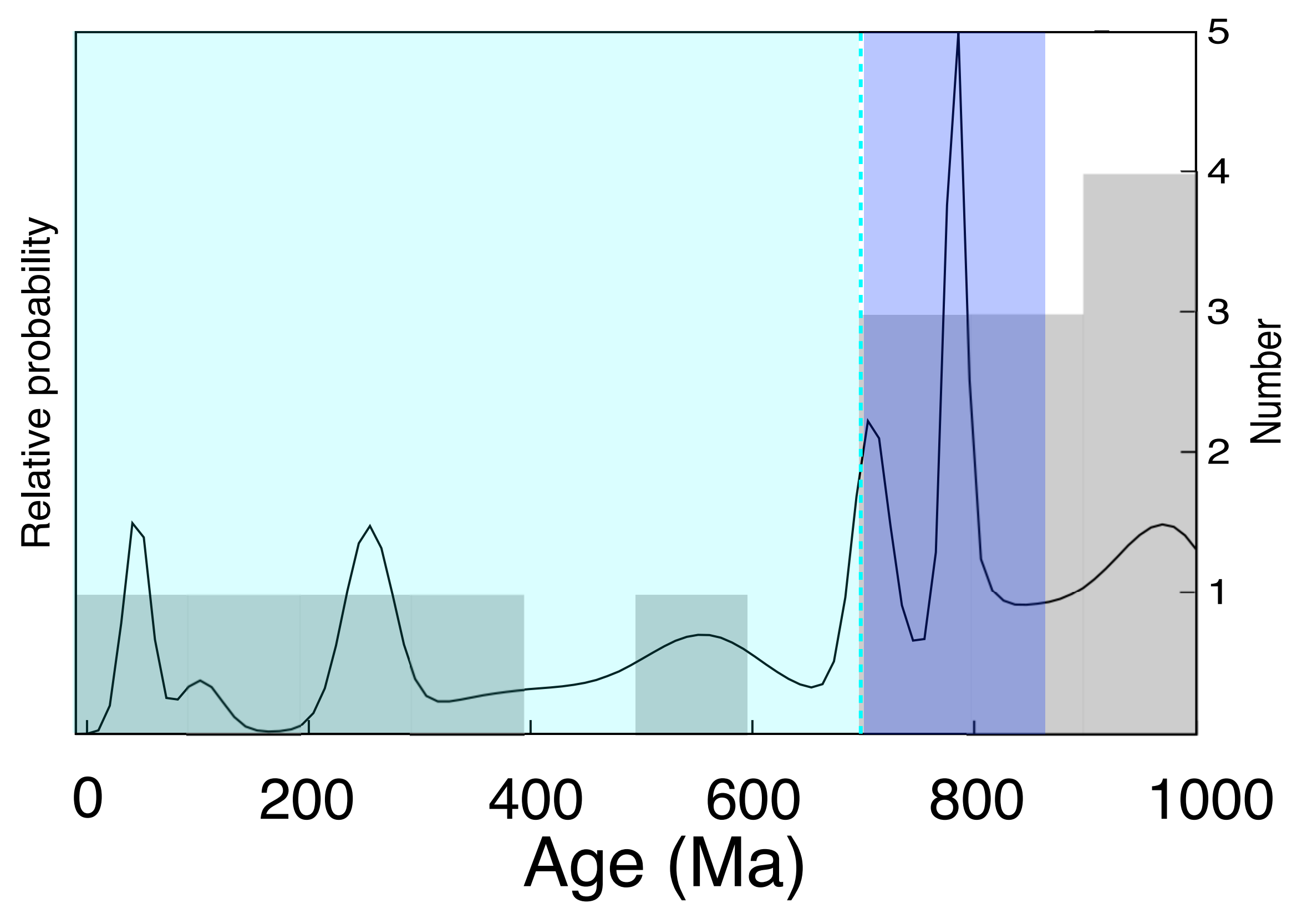

Huang et al. (2018) Bombardment workshop 


\section{Exotic impact glass spherules told a different story of lunar impact flux, yet it is not explained by a constant impact rate.}

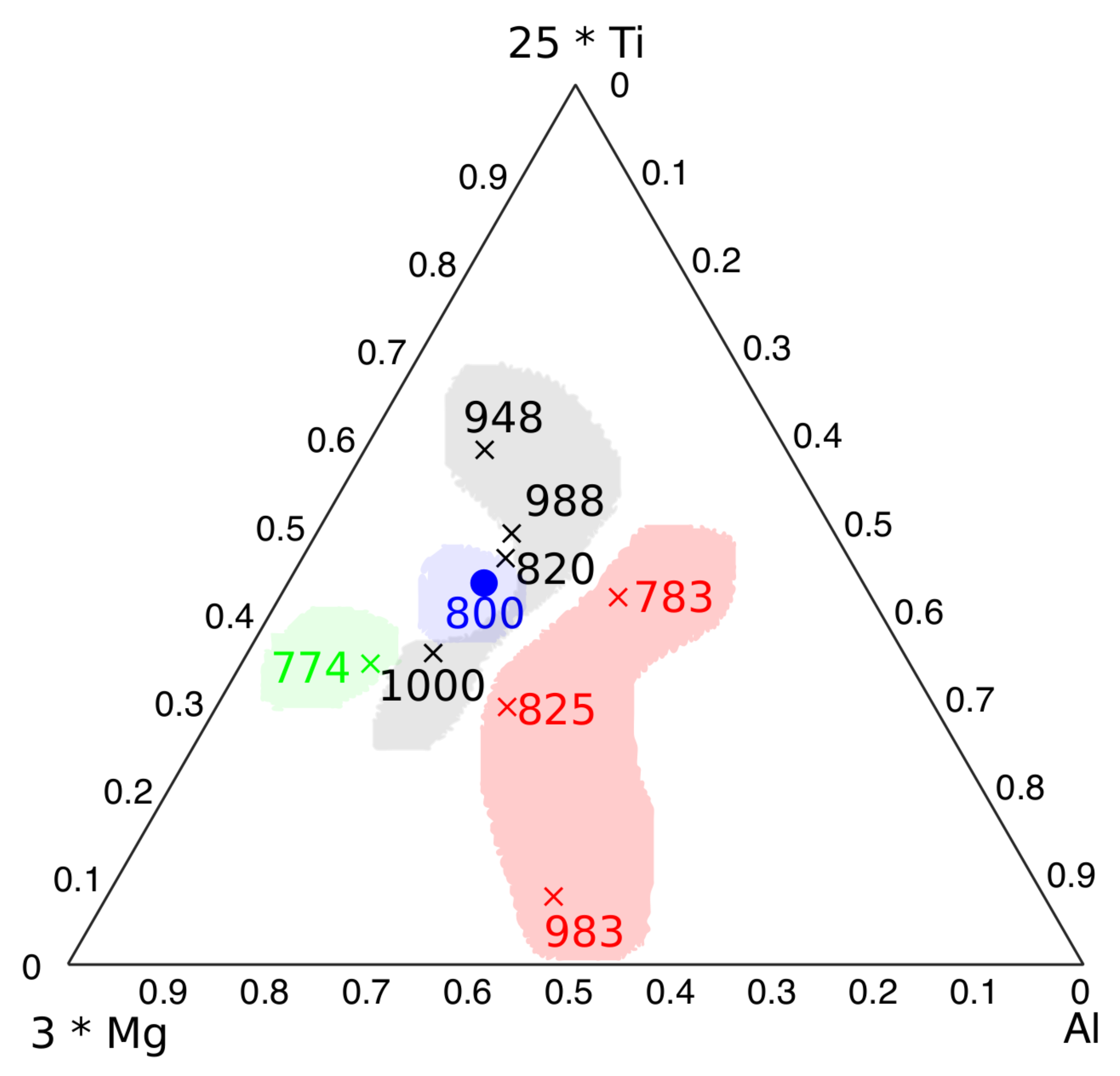

Exotic glass spherules ONLY

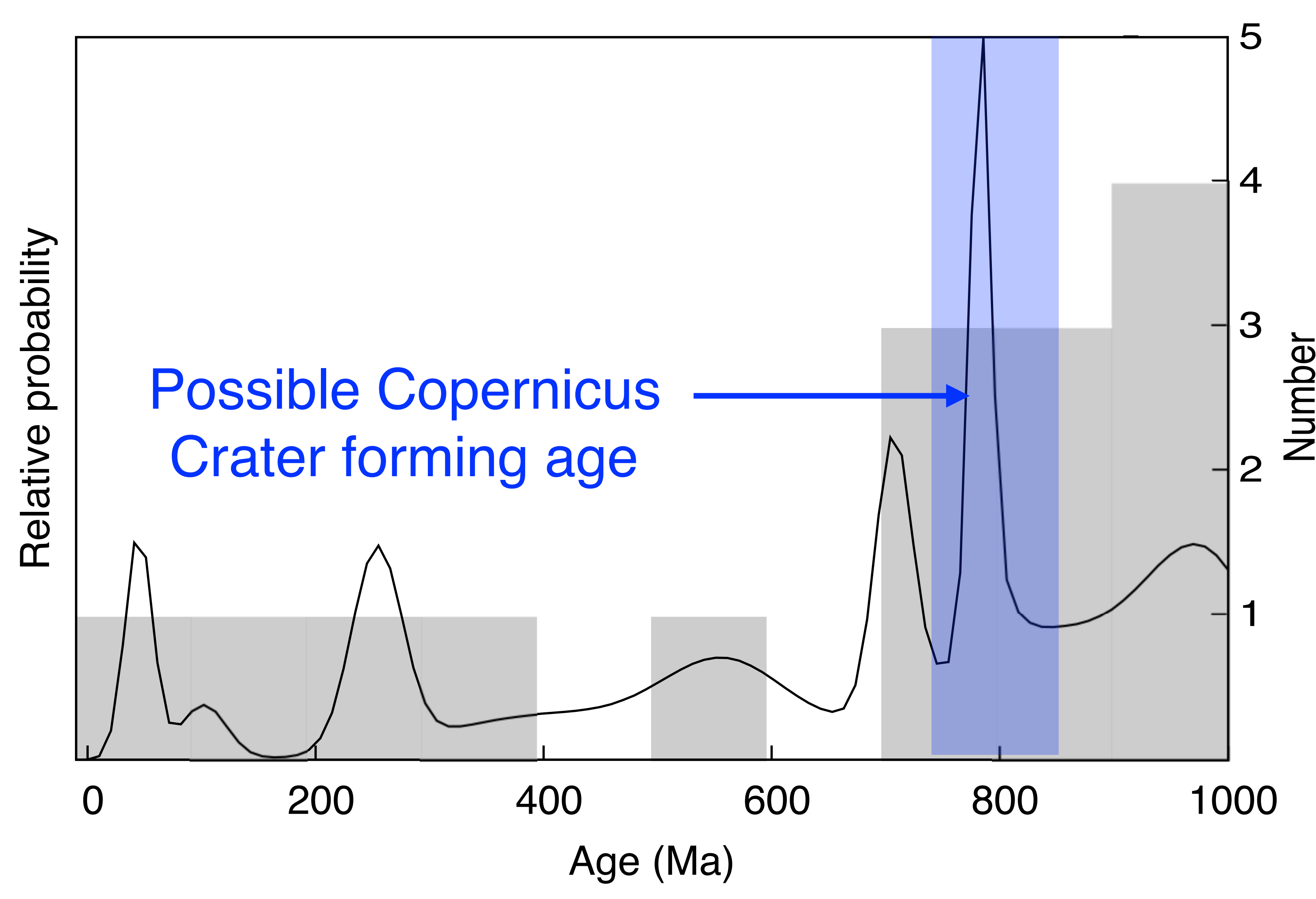

14 exotic spherules from Apollo 14, 16, and 17 sites are selected from Zellner and Delano (2015) and Zellner et al. (2009) and three new spherules in this study. 


\section{Exotic impact glass spherules told a different story of lunar impact flux, yet it is not explained by a constant impact rate.}

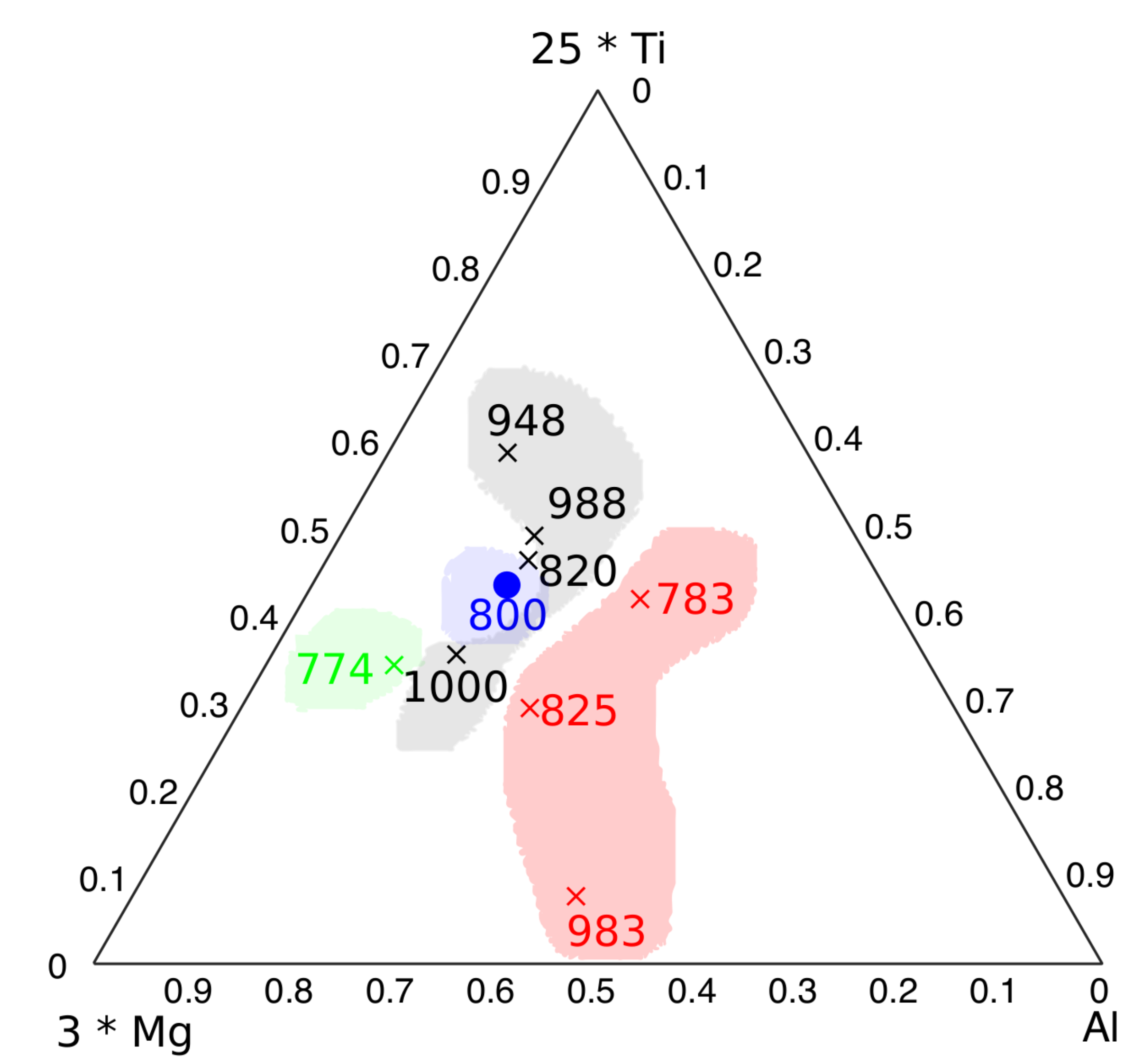

Observation 1: No tight clustering in the age distribution of simulated impacts in CTEM.
Exotic glass spherules ONLY

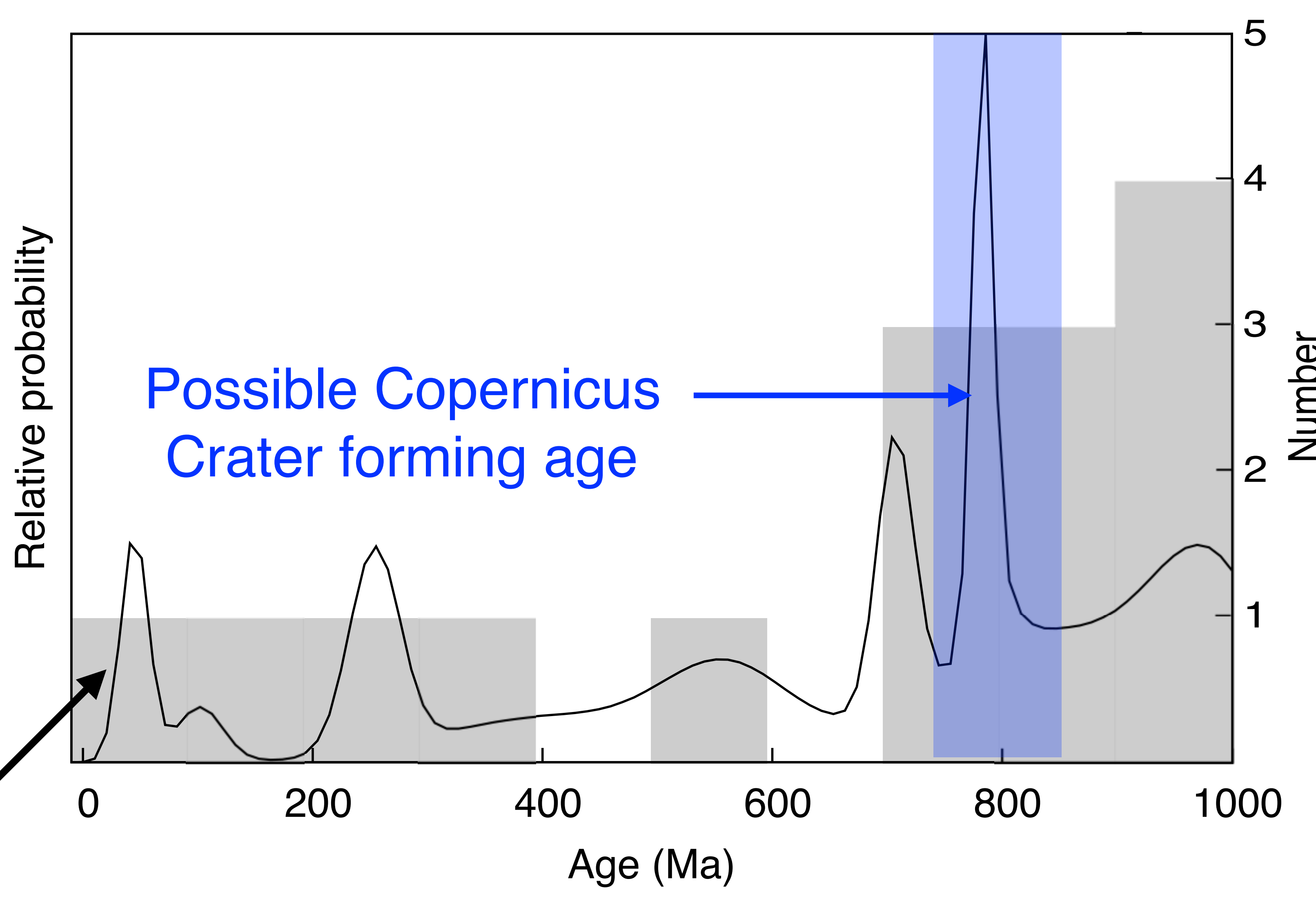

14 exotic spherules from Apollo 14, 16, and 17 sites are selected from Zellner and Delano (2015) and Zellner et al. (2009) and three new spherules in this study. 


\section{Exotic impact glass spherules told a different story of lunar impact flux, yet it is not explained by a constant impact rate.}

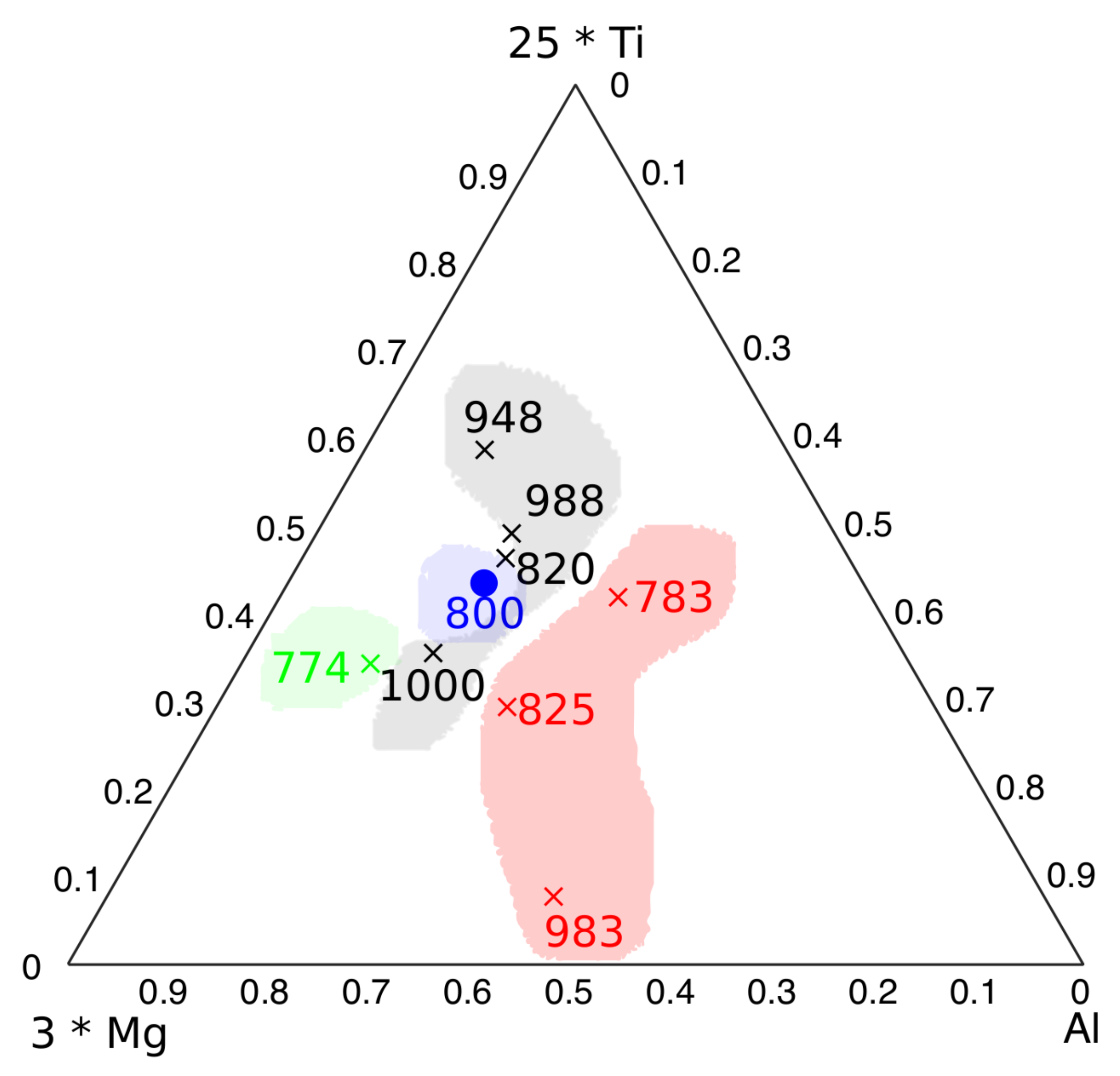

Exotic glass spherules ONLY

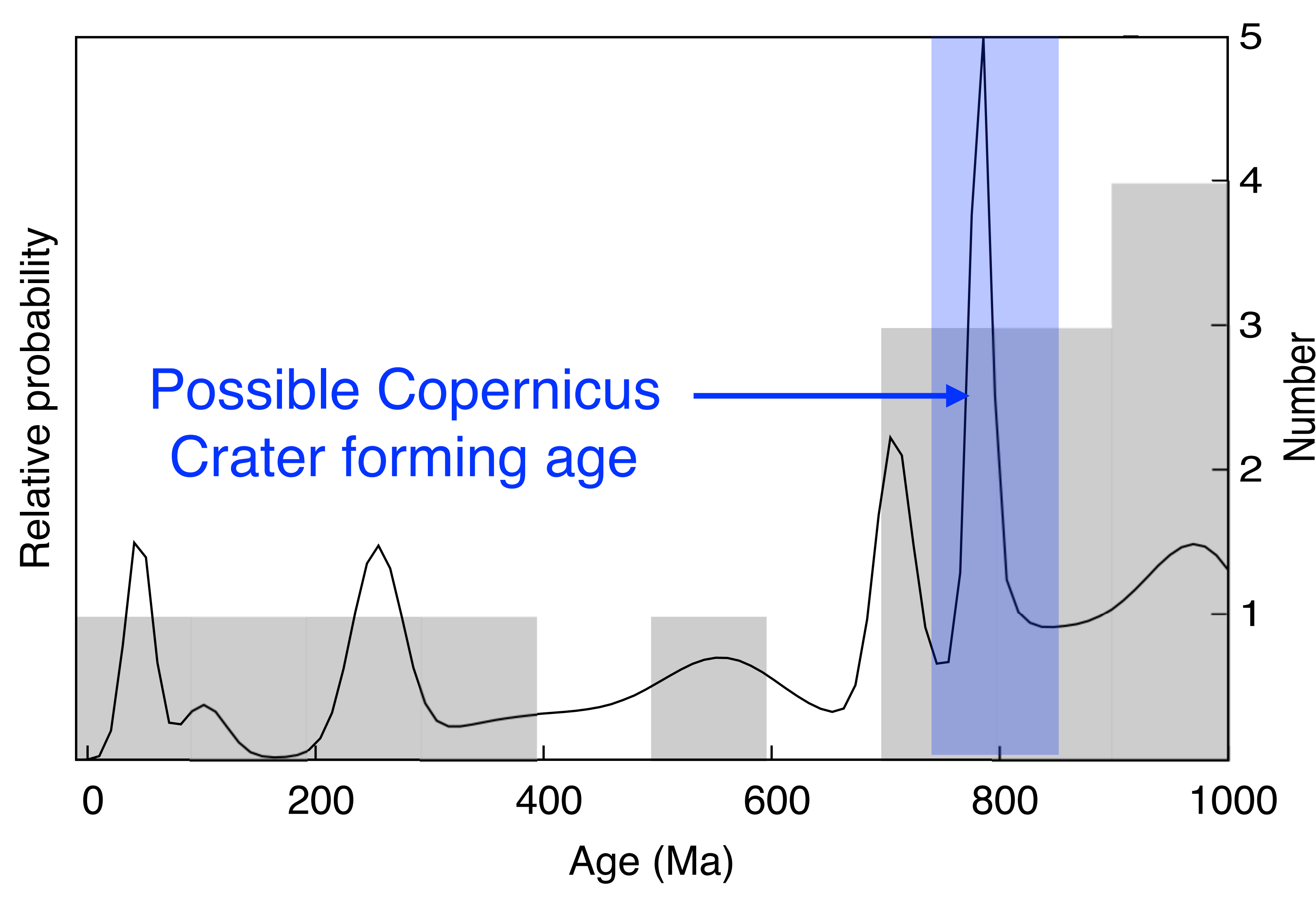

14 exotic spherules from Apollo 14, 16, and 17 sites are selected from Zellner and Delano (2015) and Zellner et al. (2009) and three new spherules in this study. 


\section{Exotic impact glass spherules told a different story of lunar impact flux, yet it is not explained by a constant impact rate.}

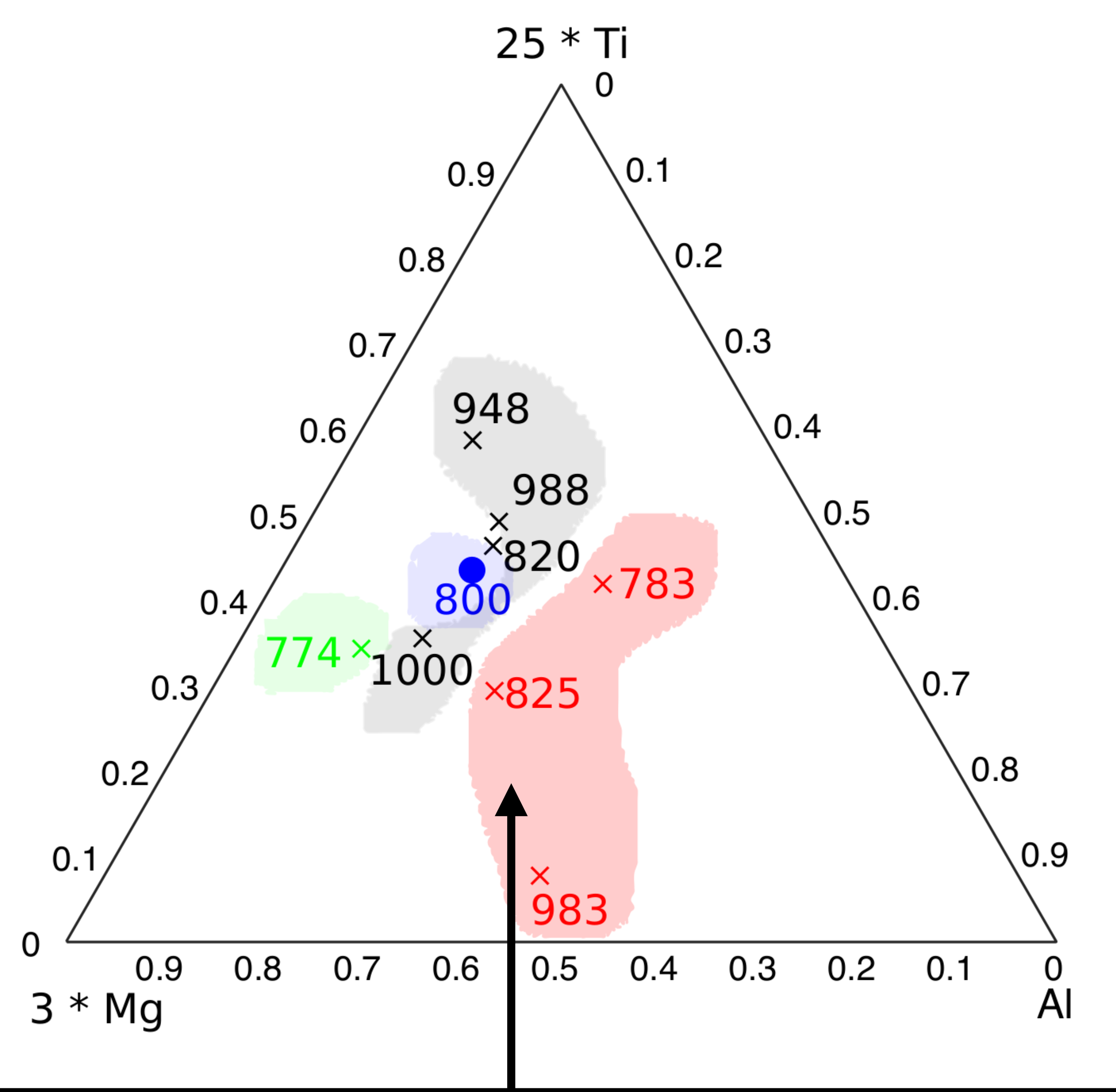

Observation 2: 800 Ma-old Exotic spherules are away from collections and in multiple landing sites.
Exotic glass spherules ONLY

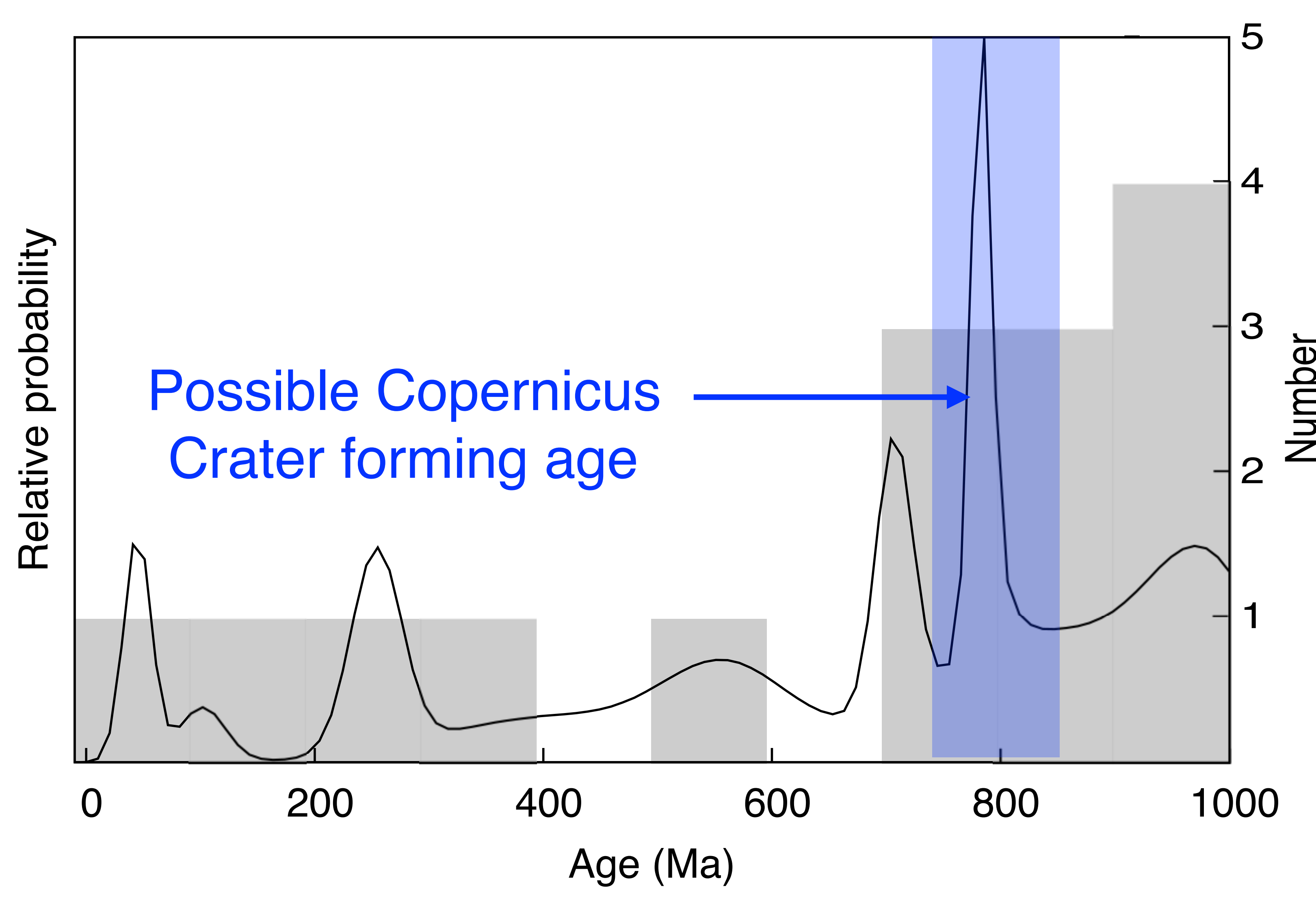

14 exotic spherules from Apollo 14, 16, and 17 sites are selected from Zellner and Delano (2015) and Zellner et al. (2009) and three new spherules in this study. 


\section{Exotic impact glass spherules told a different story of lunar impact flux, yet it is not explained by a constant impact rate.}

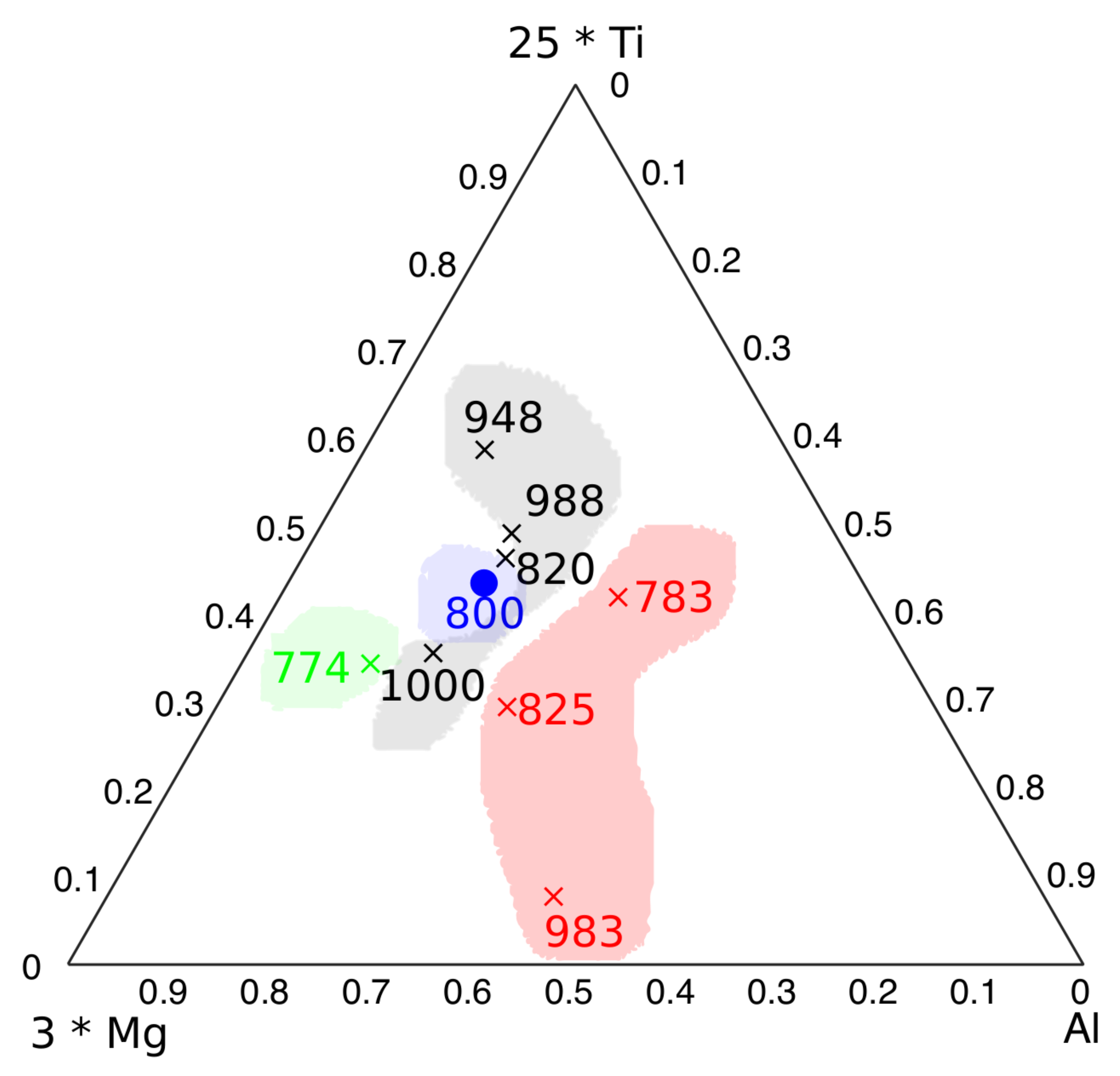

Exotic glass spherules ONLY

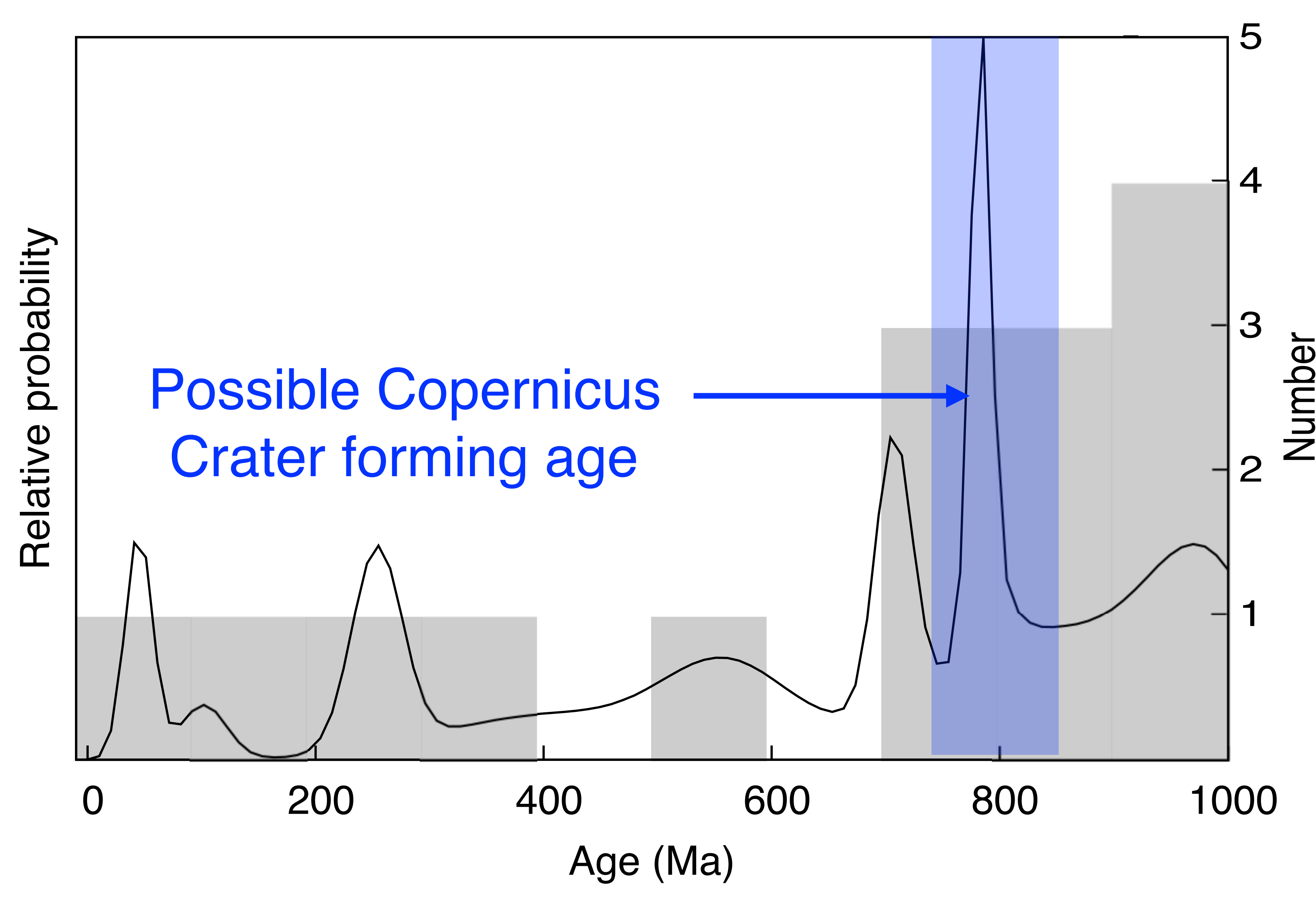

14 exotic spherules from Apollo 14, 16, and 17 sites are selected from Zellner and Delano (2015) and Zellner et al. (2009) and three new spherules in this study. 


\section{Exotic impact glass spherules told a different story of lunar impact flux, yet it is not explained by a constant impact rate.}

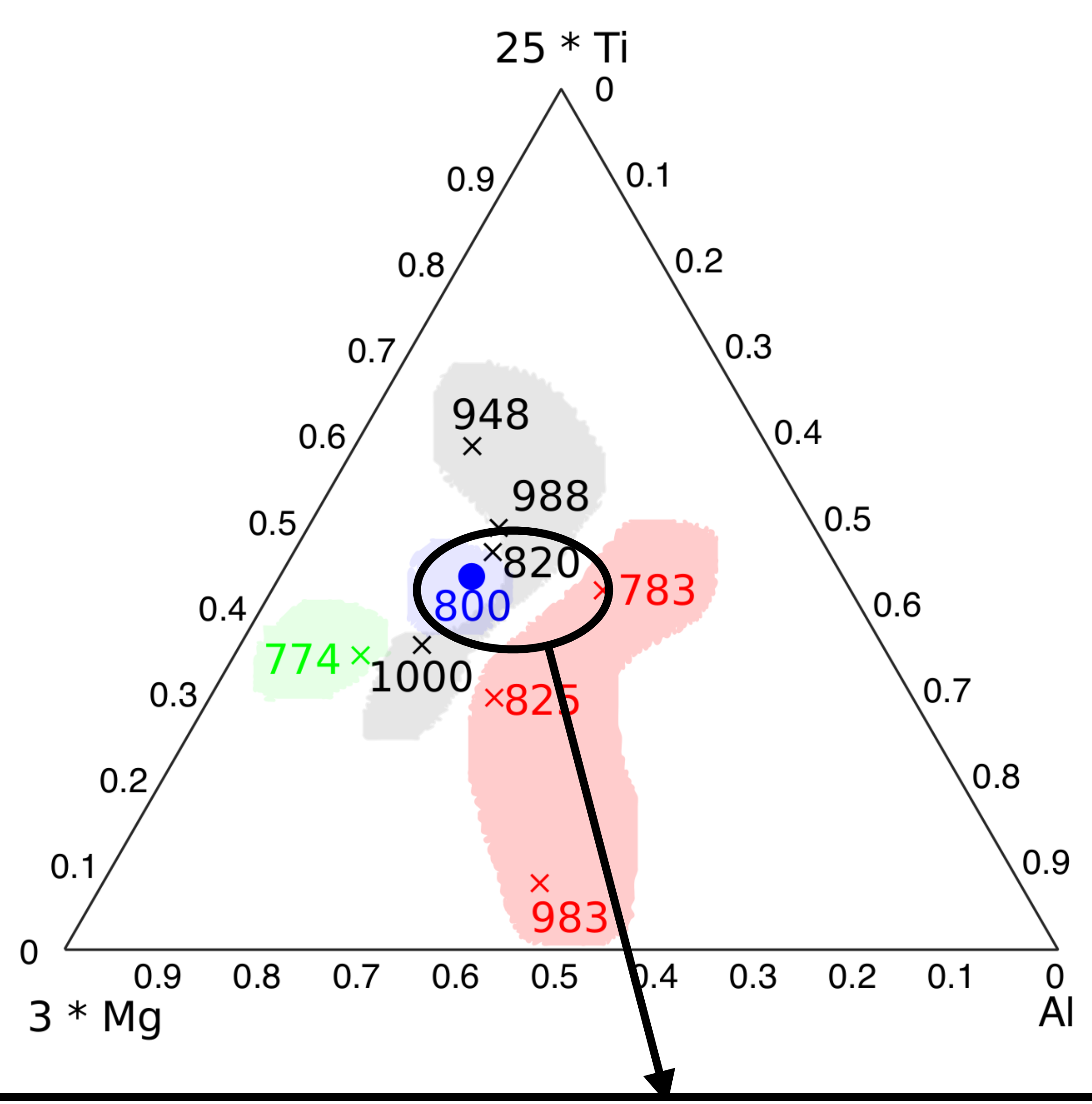

Observation 3: We found only one $800 \mathrm{Ma}-$ old, exotic spherule geochemically similar to Apollo 12 ropy glasses.
Exotic glass spherules ONLY

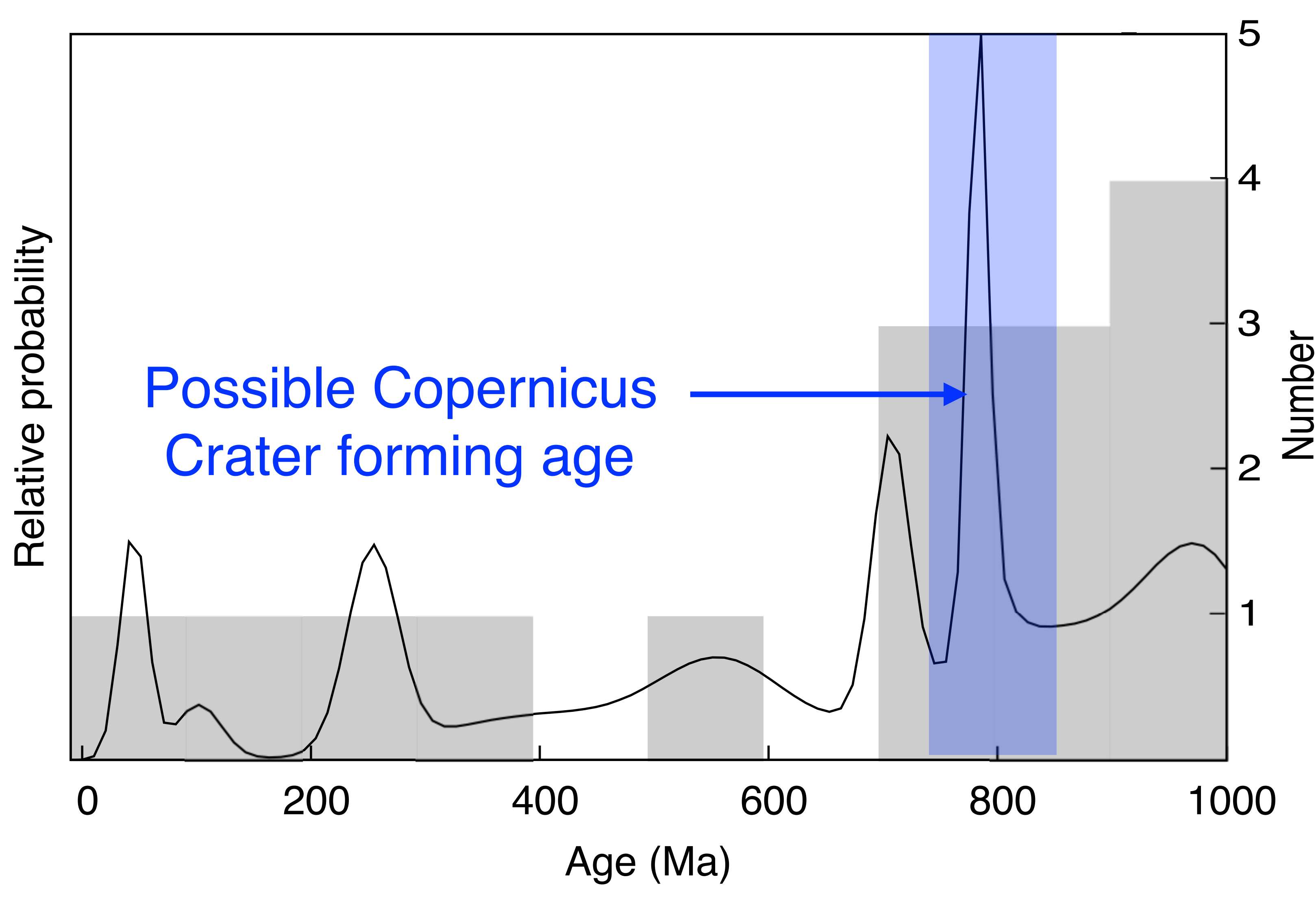

14 exotic spherules from Apollo 14, 16, and 17 sites are selected from Zellner and Delano (2015) and Zellner et al. (2009) and three new spherules in this study. 


\section{To explain the excess of $\sim 800$ Ma-old exotic glasses, we considered two possibilities.}

Hypothesis 1: There was an increase in the lunar impact flux $800 \mathrm{Ma}$ ago, and Copernicus Crater formed in this period.

Hypothesis 2: Exotic glasses were produced from re-impacting ejecta from Copernicus Crater. 


\section{To explain the excess of $\sim 800$ Ma-old exotic glasses, we considered two possibilities.}

Hypothesis 1: There was an increase in the lunar impact flux $800 \mathrm{Ma}$ ago, and Copernicus Crater formed in this period.

Hypothesis 2: Exotic glasses were produced from re-impacting ejecta from Copernicus Crater. 


\section{To explain the excess of $\sim 800$ Ma-old exotic glasses, we considered two possibilities.}

Hypothesis 1: There was an increase in the lunar impact flux $800 \mathrm{Ma}$ ago, and Copernicus Crater formed in this period.

Hypothesis 2: Exotic glasses were produced from re-impacting ejecta from Copernicus Crater.

We hoped to clarify the coincidental relationship between the formation of Copernicus Crater and the excess of exotic spherules. 


\section{To explain the excess of $\sim 800$ Ma-old exotic glasses, we considered two possibilities.}

Hypothesis 1: There was an increase in the lunar impact flux $800 \mathrm{Ma}$ ago, and Copernicus Crater formed in this period.

Hypothesis 2: Exotic glasses were produced from re-impacting ejecta from Copernicus Crater.

We hoped to clarify the coincidental relationship between the formation of Copernicus Crater and the excess of exotic spherules.

Most importantly, the melt production is dependent on impact velocity. 


\section{Fragments ejected at $>3 \mathrm{~km} / \mathrm{s}$ are suggested to be able to produce glass.}

\begin{tabular}{|l|l|l|l|}
\hline $\begin{array}{l}\text { Impact velocity } \\
(\mathrm{km} / \mathrm{s})\end{array}$ & $\begin{array}{l}\text { Peak pressure } \\
(\text { vertical impact, GPa })\end{array}$ & $\begin{array}{l}P_{m}^{i} \approx 17.5 \mathrm{GPa} a \\
(\sim 20 \% \text { porosity }\end{array}$ & $\begin{array}{l}P_{m}^{i}>30 \mathrm{GPa} \\
(0 \% \text { porosity })\end{array}$ \\
\hline 2.4 & 11.8 & $\mathrm{~N}$ & $\mathrm{~N}$ \\
\hline 2.5 & 12.8 & $\mathrm{~N}$ & $\mathrm{~N}$ \\
\hline 2.6 & 15.8 & $\mathrm{~N}$ & $\mathrm{~N}$ \\
\hline 2.8 & 16.9 & $\mathrm{~N}$ & $\mathrm{~N}$ \\
\hline 3.0 & 18.1 & $\mathrm{Y}$ & $\mathrm{N}$ \\
\hline 3.2 & 20.4 & $\mathrm{Y}$ & $\mathrm{N}$ \\
\hline
\end{tabular}

Assumed linear shock velocity:

$u_{s h}=c+s u_{p}(c=500 \mathrm{~m} / \mathrm{s}, s=3.17$, Güldemeister et al. 2013)

Peak pressure by Planar Impact Approximation (Melosh, 1989):

$P_{\text {max }}=\rho u_{s h} u_{p}\left(\rho=2297 \mathrm{kgm}^{-3}, u_{p}=0.5 v_{\text {imp }}\right)$

$P_{m}^{i}$ : Incipient peak pressure for melting (Kowitz et al. 2013; Stöffler and Langenhorst, 1994)

*: Up to $80 \%$ melt and glass observed. 


\section{Fragments ejected at $>3 \mathrm{~km} / \mathrm{s}$ are suggested to be able to produce glass.}

\begin{tabular}{|l|l|l|l|}
\hline $\begin{array}{l}\text { Impact velocity } \\
(\mathrm{km} / \mathrm{s})\end{array}$ & $\begin{array}{l}\text { Peak pressure } \\
(\text { vertical impact, GPa })\end{array}$ & $\begin{array}{l}P_{m}^{i} \approx 17.5 \mathrm{GPa} \\
(\sim 20 \% \text { porosity }\end{array}$ & $\begin{array}{l}P_{m}^{i}>30 \mathrm{GPa} \\
(0 \% \text { porosity })\end{array}$ \\
\hline 2.4 & 11.8 & $\mathrm{~N}$ & $\mathrm{~N}$ \\
\hline 2.5 & 12.8 & $\mathrm{~N}$ & $\mathrm{~N}$ \\
\hline 2.6 & 15.8 & $\mathrm{~N}$ & $\mathrm{~N}$ \\
\hline 2.8 & 16.9 & $\mathrm{~N}$ & $\mathrm{~N}$ \\
\hline 3.0 & 18.1 & $\mathrm{Y}$ & $\mathrm{N}$ \\
\hline 3.2 & 20.4 & $\mathrm{Y}$ & $\mathrm{N}$ \\
\hline
\end{tabular}

Assumed linear shock velocity:

$u_{s h}=c+s u_{p}(c=500 \mathrm{~m} / \mathrm{s}, s=3.17$, Güldemeister et al. 2013)

Peak pressure by Planar Impact Approximation (Melosh, 1989):

$P_{\text {max }}=\rho u_{s h} u_{p}\left(\rho=2297 \mathrm{kgm}^{-3}, u_{p}=0.5 v_{\text {imp }}\right)$

$P_{m}^{i}$ : Incipient peak pressure for melting (Kowitz et al. 2013; Stöffler and Langenhorst, 1994)

*: Up to $80 \%$ melt and glass observed. 


\section{Fragments ejected at $>3 \mathrm{~km} / \mathrm{s}$ are suggested to be able to produce glass.}

\begin{tabular}{|l|l|l|l|}
\hline $\begin{array}{l}\text { Impact velocity } \\
(\mathrm{km} / \mathrm{s})\end{array}$ & $\begin{array}{l}\text { Peak pressure } \\
(\text { vertical impact, GPa })\end{array}$ & $\begin{array}{l}P_{m}^{i} \approx 17.5 \mathrm{GPa} a \\
(\sim 20 \% \text { porosity }\end{array}$ & $\begin{array}{l}P_{m}^{i}>30 \mathrm{GPa} \\
(0 \% \text { porosity })\end{array}$ \\
\hline 2.4 & 11.8 & $\mathrm{~N}$ & $\mathrm{~N}$ \\
\hline 2.5 & 12.8 & $\mathrm{~N}$ & $\mathrm{~N}$ \\
\hline 2.6 & 15.8 & $\mathrm{~N}$ & $\mathrm{~N}$ \\
\hline 2.8 & 16.9 & $\mathrm{~N}$ & $\mathrm{~N}$ \\
\hline 3.0 & 18.1 & $\mathrm{Y}$ & $\mathrm{N}$ \\
\hline 3.2 & 20.4 & $\mathrm{Y}$ & $\mathrm{N}$ \\
\hline
\end{tabular}

Copernicus Crater secondary craters cannot generate melt.

Assumed linear shock velocity:

$u_{s h}=c+s u_{p}(c=500 \mathrm{~m} / \mathrm{s}, \mathrm{s}=3.17$, Güldemeister et al. 2013)

Peak pressure by Planar Impact Approximation (Melosh, 1989):

$P_{\text {max }}=\rho u_{s h} u_{p}\left(\rho=2297 \mathrm{kgm}^{-3}, u_{p}=0.5 v_{\text {imp }}\right)$

$P_{m}^{i}$ : Incipient peak pressure for melting (Kowitz et al. 2013; Stöffler and Langenhorst, 1994)

*: Up to $80 \%$ melt and glass observed. 
We combined fragmentation and $\mathrm{N}$-body orbit dynamics codes, and generated a SFD of Copernicus Crater's ejecta fragments.

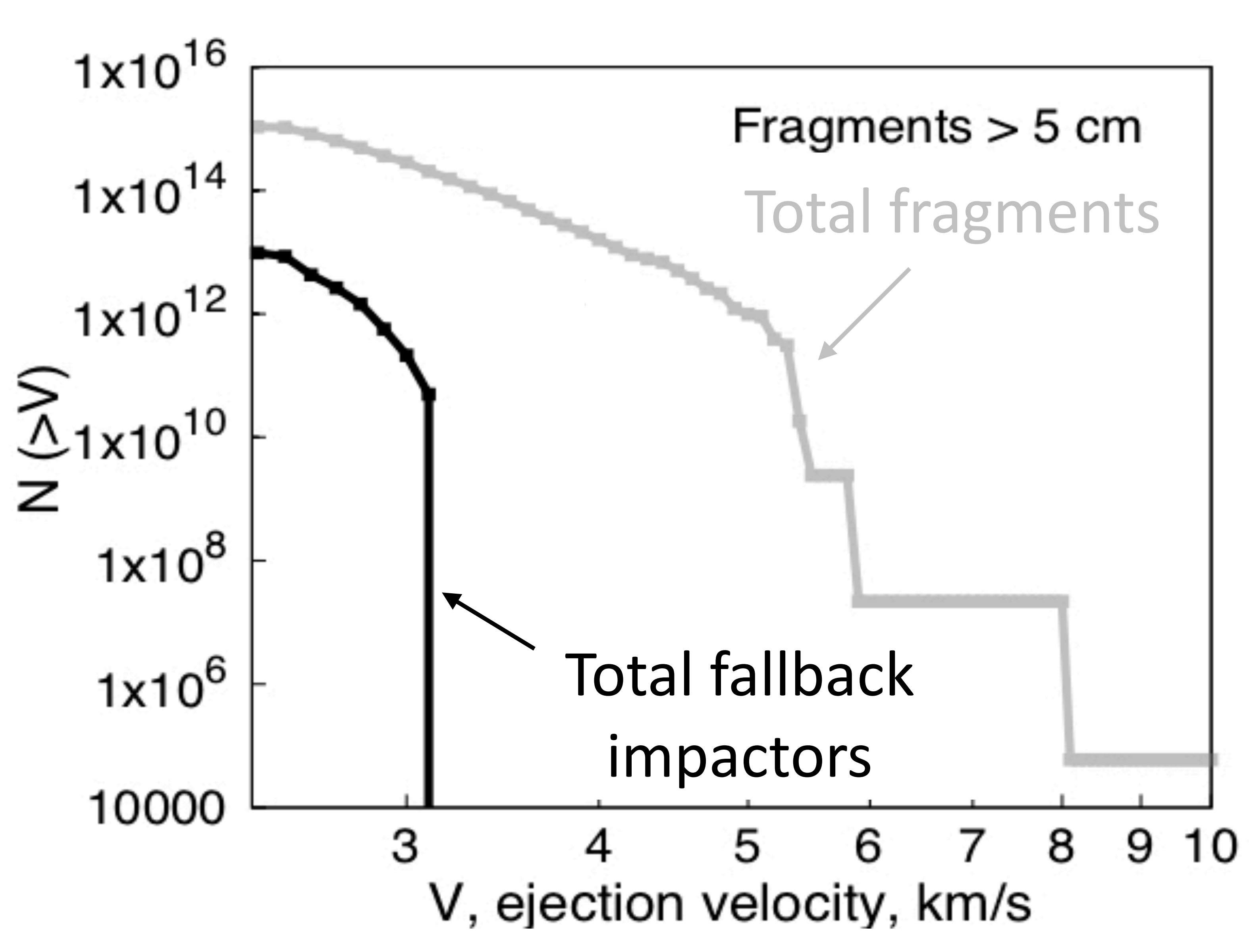

Huang et al. Bombardment workshop (2018)
SALES_2 run conditions

\begin{tabular}{|c|c|c|c|}
\hline $\begin{array}{c}\text { Impactor } \\
\text { diameter }\end{array}$ & $\begin{array}{c}\text { Impact } \\
\text { velocity }\end{array}$ & $\begin{array}{c}\text { Target } \\
\text { material }\end{array}$ & $\begin{array}{c}\text { Projectile } \\
\text { material }\end{array}$ \\
\hline $7 \mathrm{~km}$ & $10 \mathrm{~km} / \mathrm{s}$ & Basalt & Basalt \\
\hline
\end{tabular}

Elliott and Melosh (2018)

\begin{tabular}{|c|c|c|c|c|c|c|}
\hline $\begin{array}{c}\text { REBOUND } \\
\text { Luanch } \\
\text { velocity }(\mathrm{km} / \mathrm{s})\end{array}$ & 2.4 & 2.5 & 2.6 & 2.8 & 3.0 & 3.2 \\
\hline $\begin{array}{c}\text { Moon }(\% \text { of } \\
1000 \text { teat } \\
\text { particles })\end{array}$ & 3.9 & 1.9 & 0.9 & 0.7 & 0.2 & 0.0 \\
\hline
\end{tabular}

Rein et al. (2012) 
We combined fragmentation and $\mathrm{N}$-body orbit dynamics codes, and generated a SFD of Copernicus Crater's ejecta fragments.

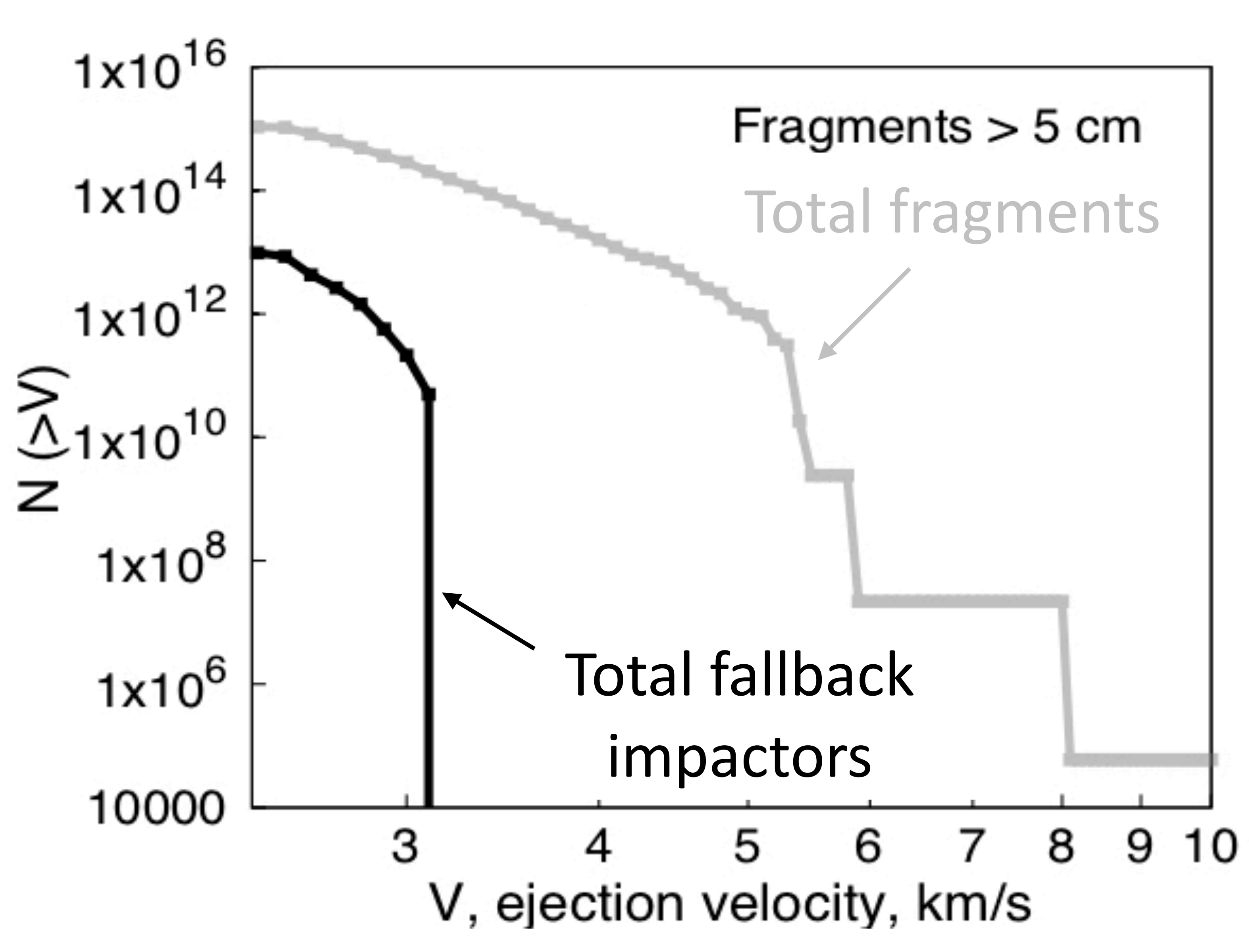

Huang et al. Bombardment workshop (2018)
SALES_2 run conditions

\begin{tabular}{|c|c|c|c|}
\hline $\begin{array}{c}\text { Impactor } \\
\text { diameter }\end{array}$ & $\begin{array}{c}\text { Impact } \\
\text { velocity }\end{array}$ & $\begin{array}{c}\text { Target } \\
\text { material }\end{array}$ & $\begin{array}{c}\text { Projectile } \\
\text { material }\end{array}$ \\
\hline $7 \mathrm{~km}$ & $10 \mathrm{~km} / \mathrm{s}$ & Basalt & Basalt \\
\hline
\end{tabular}

Elliott and Melosh (2018)

\begin{tabular}{|c|c|c|c|c|c|c|}
\hline $\begin{array}{c}\text { REBOUND } \\
\text { Luanch } \\
\text { velocity }(\mathrm{km} / \mathrm{s})\end{array}$ & 2.4 & 2.5 & 2.6 & 2.8 & 3.0 & 3.2 \\
\hline $\begin{array}{c}\text { Moon }(\% \text { of } \\
1000 \text { teat } \\
\text { particles })\end{array}$ & 3.9 & 1.9 & 0.9 & 0.7 & 0.2 & 0.0 \\
\hline
\end{tabular}

Rein et al. (2012) 
Considering that the lower velocity makes glass formation more difficult, sesquinary-forming spherules appears negligible.

All Copernicus Crater-forming craters SFD

(> lunar escape velocity)

For only $\sim 3 \mathrm{~km} / \mathrm{s}$

Glass-forming SFD

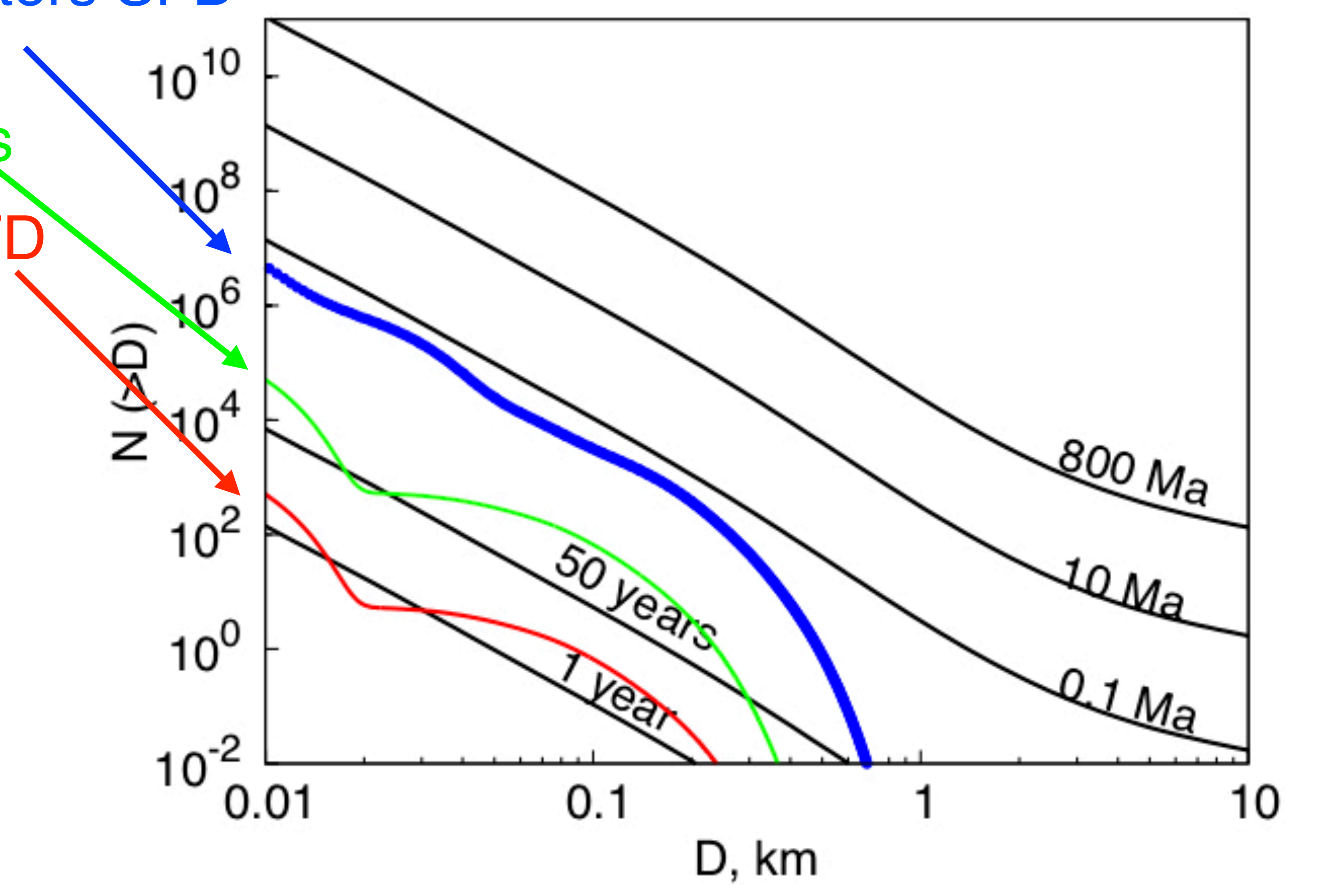


Considering that the lower velocity makes glass formation more difficult, sesquinary-forming spherules appears negligible.

All Copernicus Crater-forming craters SFD

(> lunar escape velocity)

For only $\sim 3 \mathrm{~km} / \mathrm{s}$

Glass-forming SFD

Copernicus Crater may have been the largest crater produced in a short-lived impact spike at $\sim 800 \mathrm{Ma}$ as proposed by Zellner et al. (2009).
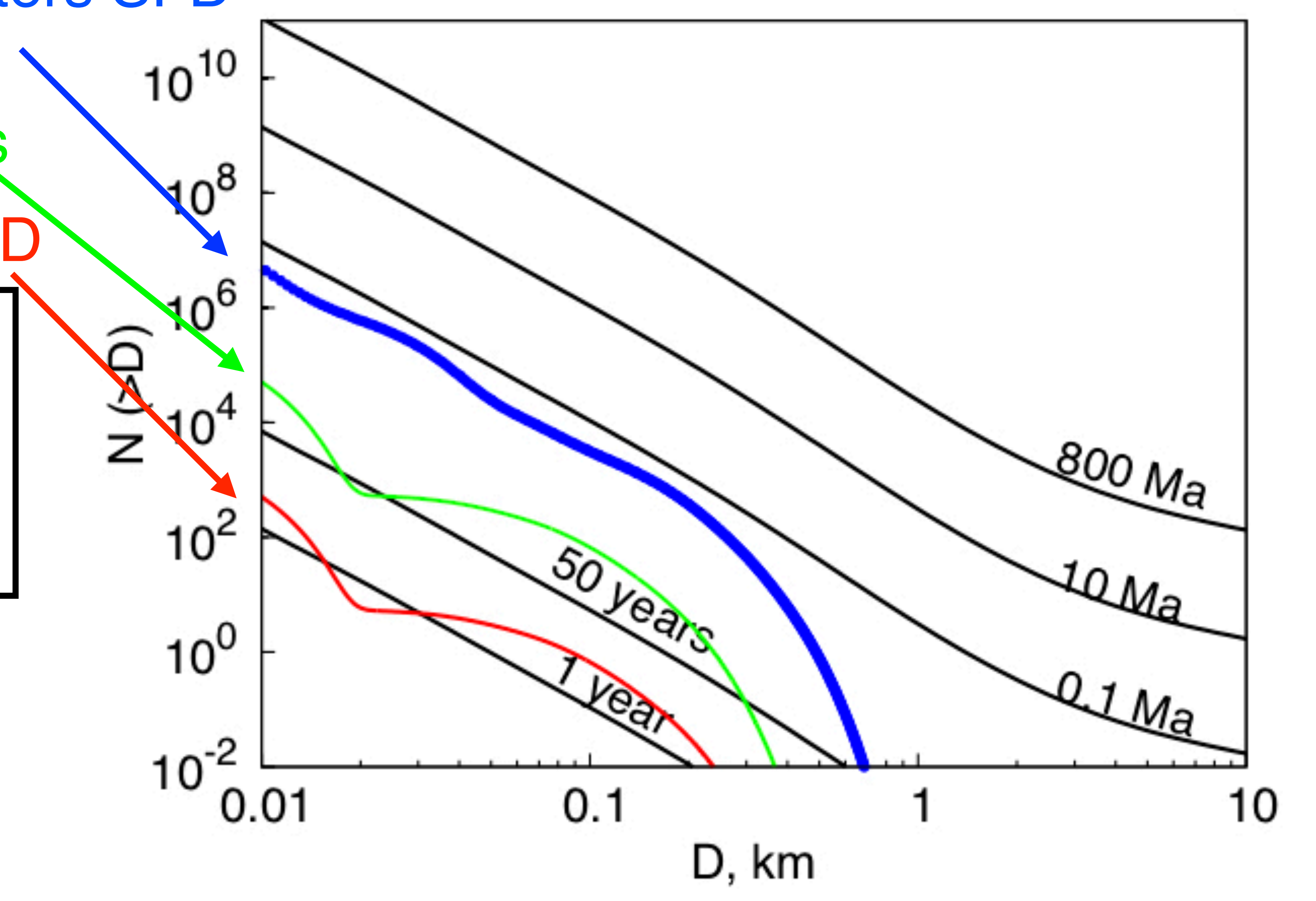
Considering that the lower velocity makes glass formation more difficult, sesquinary-forming spherules appears negligible.

All Copernicus Crater-forming craters SFD

( $>$ lunar escape velocity)

For only $\sim 3 \mathrm{~km} / \mathrm{s}$

Glass-forming SFD

Copernicus Crater may have been the largest crater produced in a short-lived impact spike at $\sim 800 \mathrm{Ma}$ as proposed by Zellner et al. (2009).

Or a link between geochemical composition of exotic glass spherules and Copernicus Crater needs to be further assessed.

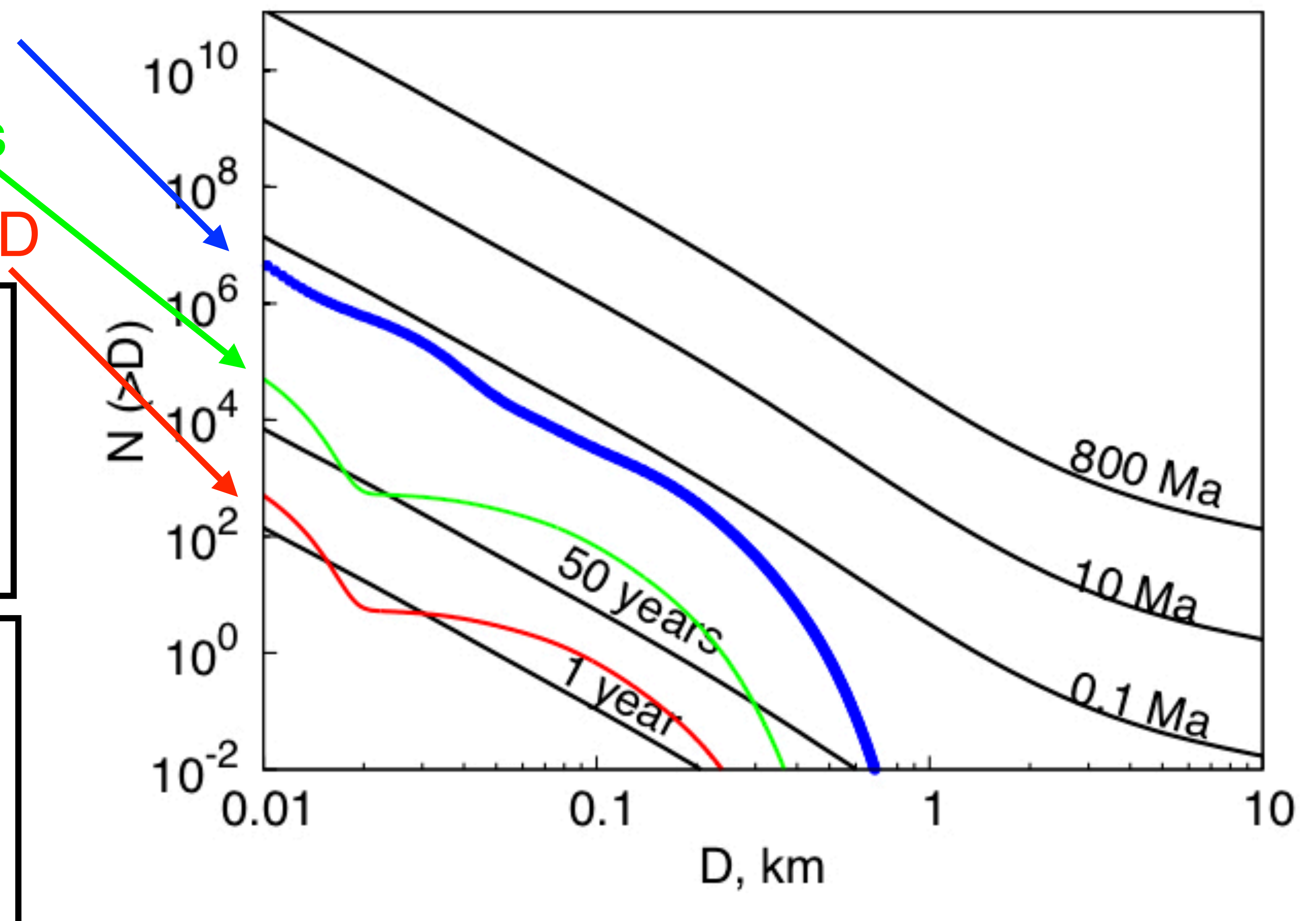




\section{Implications}

- The excess of lunar impact glass spherules in the last $500 \mathrm{Ma}$ can be explained by our depth-dependent sampling bias model without changing the impact flux, but this does not rule out a possibility of a change in the lunar impact flux.

- Our identified fourteen exotic glass spherules show an excess of 800 Ma ages, which is consistent with an initial finding of Zellner et al. (2009).

- Due to a negligible amount of Copernicus Crater-forming spherules, Copernicus Crater alone cannot explain the excess of $800 \mathrm{Ma}$-old, exotic spherules, suggesting a possibility of a short-lived spike $800 \mathrm{Ma}$ ago on the Moon.

- Considering a target heterogeneity of Copernicus Crater regime, a further geochemical analysis for our identified "exotic" spherules and the subsurface of Copernicus Crater is needed. 
Terrestrial microtektite distributions from crater's center may shed some light on the physics of impact glass spherules.
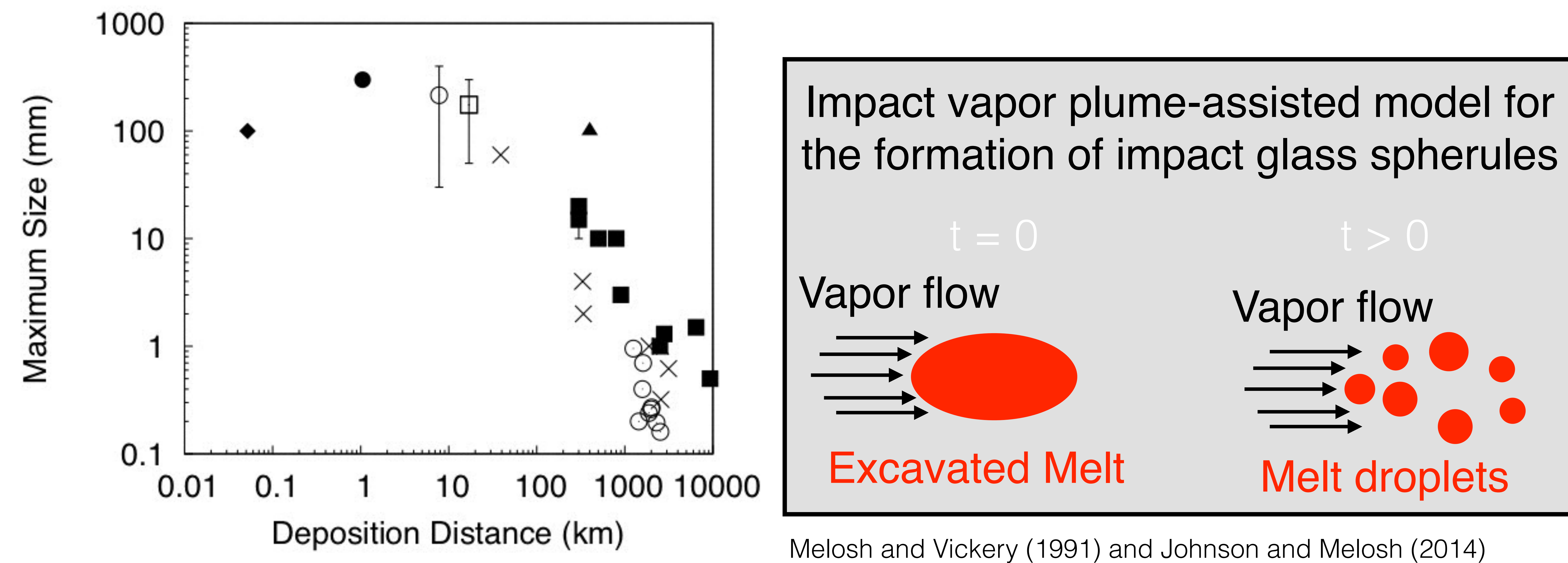

Melosh and Vickery (1991) and Johnson and Melosh (2014)

$\square$ Chicxulub (34 km) $\times$ Chesapeake Bay (12.6 km) $\square$ Ries (9.9 km)

$\bigodot$ Bosumtwi $(4 \mathrm{~km}) \bigcirc \operatorname{Lonar}(600 \mathrm{~m})>\operatorname{Kamil}(20 \mathrm{~m})$

$\Delta$ Apollo 12 Ropy glasses (Copernicus, 38 km) Huang et al. (2018) GRL 
Terrestrial microtektite distributions from crater's center may shed some light on the physics of impact glass spherules.
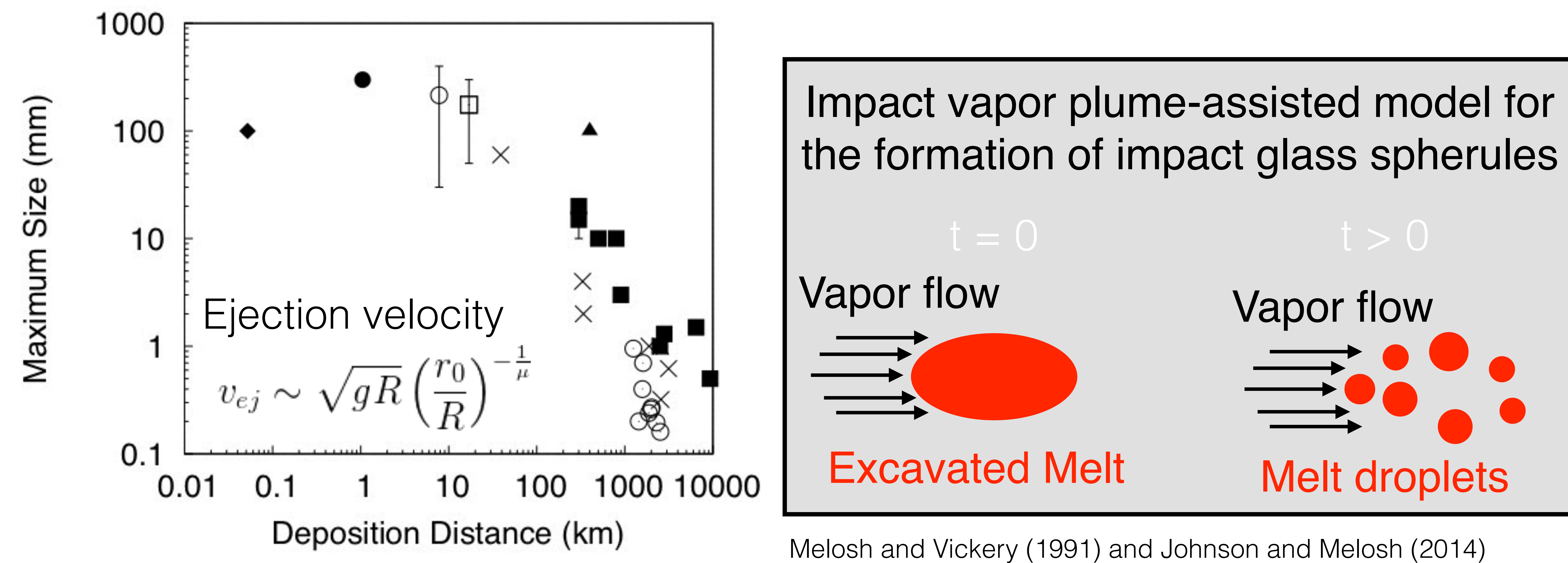

Melosh and Vickery (1991) and Johnson and Melosh (2014)

Chicxulub (34 km) $\times$ Chesapeake Bay (12.6 km) $\square$ Ries (9.9 km)

$\bigodot$ Bosumtwi $(4 \mathrm{~km}) \bigcirc \operatorname{Lonar}(600 \mathrm{~m})>\operatorname{Kamil}(20 \mathrm{~m})$

$\Delta$ Apollo 12 Ropy glasses (Copernicus, 38 km) Huang et al. (2018) GRL 
Terrestrial microtektite distributions from crater's center may shed some light on the physics of impact glass spherules.

Lunar landing distance (radii)
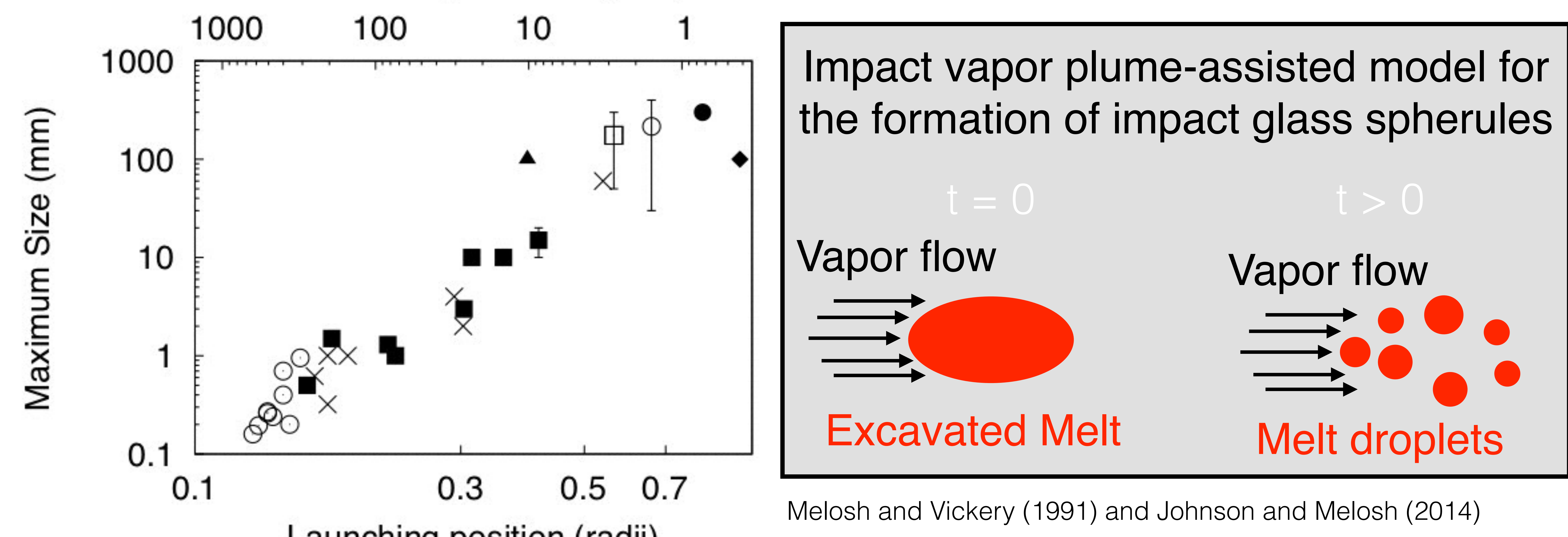

Launching position (radii)

Melosh and Vickery (1991) and Johnson and Melosh (2014)

$\square$ Chicxulub (34 km) $\times$ Chesapeake Bay (12.6 km) $\square$ Ries (9.9 km)

$\bigodot$ Bosumtwi (4 km) Lonar $(600 \mathrm{~m})>\operatorname{Kamil}(20 \mathrm{~m})$

$\Delta$ Apollo 12 Ropy glasses (Copernicus, 38 km) Huang et al. (2018) GRL 
Terrestrial microtektite distributions from crater's center may shed some light on the physics of impact glass spherules.

Lunar landing distance (radii)
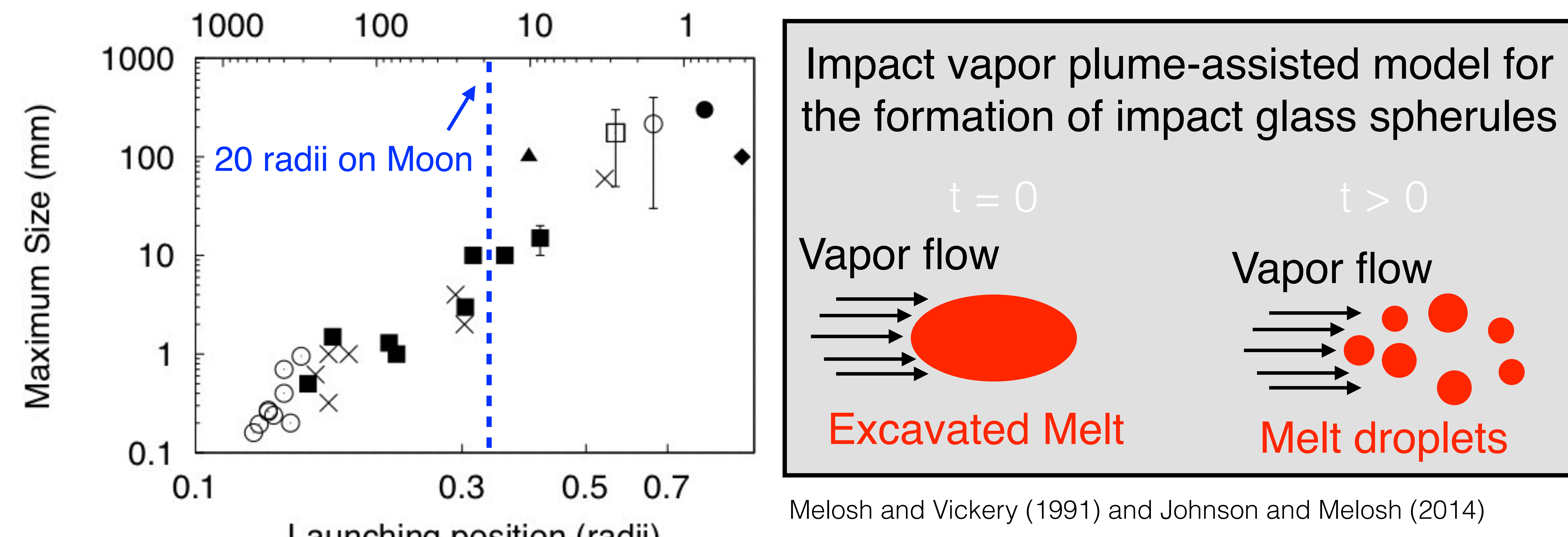

Launching position (radii)

Melosh and Vickery (1991) and Johnson and Melosh (2014)

$\square$ Chicxulub (34 km) $\times$ Chesapeake Bay (12.6 km) $\square$ Ries (9.9 km)

$\bigodot$ Bosumtwi (4 km) Lonar $(600 \mathrm{~m})>\operatorname{Kamil}(20 \mathrm{~m})$

$\Delta$ Apollo 12 Ropy glasses (Copernicus, 38 km) Huang et al. (2018) GRL 